\title{
Review Article \\ Review of Solid State Hydrogen Storage Methods Adopting Different Kinds of Novel Materials
}

\author{
Renju Zacharia ${ }^{1,2}$ and Sami ullah Rather ${ }^{3}$ \\ ${ }^{1}$ Institut de Recherche sur l'Hydrogène, Université du Québec à Trois-Rivières, P.O. Box 500, Trois-Rivieres, QC, Canada G9A 5H7 \\ ${ }^{2}$ Gas Processing Center, College of Engineering, Qatar University, P.O. Box 2713, Doha, Qatar \\ ${ }^{3}$ Chemical and Materials Engineering Department, King Abdulaziz University, P.O. Box 80204, Jeddah 21589, Saudi Arabia
}

Correspondence should be addressed to Sami ullah Rather; rathersami@kau.edu.sa

Received 19 June 2015; Accepted 19 August 2015

Academic Editor: Yuan Chen

Copyright (C) 2015 R. Zacharia and S. U. Rather. This is an open access article distributed under the Creative Commons Attribution License, which permits unrestricted use, distribution, and reproduction in any medium, provided the original work is properly cited.

\begin{abstract}
Overview of advances in the technology of solid state hydrogen storage methods applying different kinds of novel materials is provided. Metallic and intermetallic hydrides, complex chemical hydride, nanostructured carbon materials, metal-doped carbon nanotubes, metal-organic frameworks (MOFs), metal-doped metal organic frameworks, covalent organic frameworks (COFs), and clathrates solid state hydrogen storage techniques are discussed. The studies on their hydrogen storage properties are in progress towards positive direction. Nevertheless, it is believed that these novel materials will offer far-reaching solutions to the onboard hydrogen storage problems in near future. The review begins with the deficiencies of current energy economy and discusses the various aspects of implementation of hydrogen energy based economy.
\end{abstract}

\section{Introduction}

Currently mankind depends completely on nonrenewable resources such as natural gas, coal, and petroleum to fulfill energy needs. This exquisite dependence on nonrenewable energy sources has twofold consequences: the continuous depletion of energy sources at an alarming rate and the adverse health and environmental impacts $[1,2]$. These repercussions have compelled scientists, technologists, economists, and policy-makers to search for alternate, sustainable, and less-polluting energy sources [3-5]. Hydrogen is considered as a clean and sustainable energy carrier, which ultimately can replace nonrenewable fossil fuels and therefore can resolve the availability, environmental, and health concerns of the latter $[6,7]$. However, the implementation of an energy economy based on this sustainable and clean fuel is not straight forward but suffers severe hurdles in the production, storage, delivery, and utilization of hydrogen [8-10]. Amongst the various problems that exist in the successful materialization of hydrogen fuel based economy, the formulation of a safe, economical, and efficient hydrogen storage method poses the most confronting challenge [1113]. This is particularly true, if the utilization of hydrogen fuel in the transportation sector is considered $[6,14]$. The transportation sector presently relies exclusively on refined petroleum products that are increasingly unaffordable [6]. This dependence can be eliminated by employing hydrogen as the transportation fuel, which requires high-density hydrogen storage medium $[6,15]$. Therefore, there is considerable enthusiasm in devising novel hydrogen media that can be utilized in the transportation sector. Carbon nanotubes (CNTs), metal-doped carbon nanotubes (M/CNT), metal-organic frameworks (MOFs), metal-doped metal-organic frameworks (M/MOFs), covalent-organic frameworks (COFs), zeolites, and clathrates are novel nanoporous materials which can store large quantities of hydrogen [16-23]. Likewise, complex chemical and metallic hydrides represent compounds in which large quantities of hydrogen are stored via chemical bonding $[16,22]$. Though studies on their hydrogen storage and release properties of these materials are in the rudimentary stages, they are envisaged to offer long-term onboard hydrogen storage solutions.

The central focus of this review is the recent advances in the solid state hydrogen storage techniques using aforementioned materials. The review is organized as follows: in the introductory section, we present the challenges and 


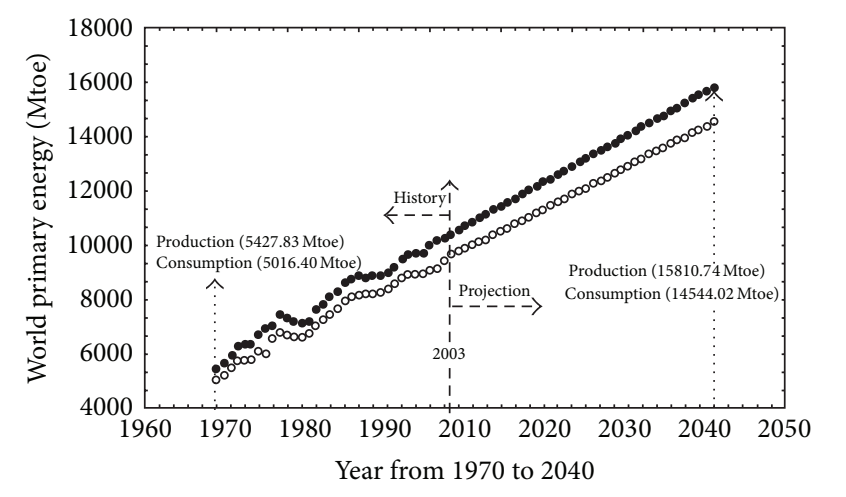

- Production (correlation coefficient $(r)=0.99919)$ (determination coefficient $\left(r^{2}\right)=0.99838$ )

- Consumption (correlation coefficient $(r)=0.99922$ ) (determination coefficient $\left(r^{2}\right)=0.99844$ )

FIgURE 1: The global variation in the production and consumption of fossil fuels. All fuels are converted into the units of million tons of oil equivalent (Mtoe). The production and consumption between 2003 and 2040 are predicted based on past data [9].

problems of the present fossil-fuel based energy economy. The fundamental reasons for adopting a hydrogen fuel based economy are presented subsequently. In the second section, the characteristics and benefits of hydrogen energy economy are detailed. Further, various elements of hydrogen energy infrastructure and requirements of these elements are dealt in this section. The final section of the review presents the problems specific to onboard hydrogen storage. This is followed by the quantitative explanations of the design targets for a successful hydrogen storage medium. The hydrogen storage behavior of nanostructured carbon nanotubes (CNTs), metal-doped carbon nanotubes (M/CNT), metal-organic frameworks (MOFs), metal-doped metalorganic frameworks (M/MOFs), covalent-organic frameworks (COFs), zeolites, complex chemical and metallic hydrides, and clathrates is presented subsequently.

Challenges and Problems in the Present Energy Economy. The present energy economy is based on fossil fuels which comprise mainly three components: petroleum, natural gas, and coal [24]. These nonrenewable forms of energy cannot indefinitely serve as the principal energy sources owing to their continuous depletion and the tremendous rise in their demand. The disproportionate rate of the global production and consumption of fossil fuels is shown in Figure $1[9,24]$. In Figure 1, the projected trend between the years 2003 and 2040 is expected to cover the world energy needs only if the population remains constant $[9,25,26]$. The massive increase in the energy demand towards the middle of this century is closely associated with the predicted drastic world population growth, technological advances, and increased living standards [9]. Further, on a global scale, the fuel supply demand will be increasingly higher when highly populated countries expand their economies and become more energy intensive.
According to various energy specialists, the fossil-fuel reserves that are presently available can support a maximum of 40 years for petroleum, 60 years for natural gas, and 156 years for coal $[9,24]$. It can be noted that less polluting fossil fuels, such as natural gas and petroleum, are in higher demand and have low reserves while fuels, such as coal, are available for longer duration but pose severe environmental threats $[24,27]$. Due to the disparity in the utilization pattern and future availability of these fuels, it is expected that they are likely to become unaffordable and unavailable in the near future. This predicted scarcity of fossil-fuel reserves together with the foreseen increase in energy consumption threatens the energy and economic security problems worldwide. Thus, attaining a greater energy security by reducing the dependence on depleting nonrenewable energy sources serves as the primary motivation for the implementation of a sustainable energy economy.

The second confronting problem associated with the indiscriminate use of fossil fuels is the diminishing air quality and subsequent air pollution, while utilizing the fossil fuels [28]. The release of tar, dust, and harmful gases such as $\mathrm{CO}_{2}, \mathrm{SO}_{2}$, and $\mathrm{NO}_{2}$ volatile organic components (VOCs) during the combustion of the fossil fuels results in local health hazards $[28,29]$. On the other hand, the increased presence of greenhouse gases (GHGs), such as $\mathrm{CO}_{2}, \mathrm{NO}_{2}$, induces fast changes in the global climate [30]. With the consumption of nonrenewable fuels at a predicted pace of $1000 \mathrm{EJ}(1 \mathrm{EJ}=$ $10^{18} \mathrm{~J}$ ), the increase in annual average temperature of earth is predicted to be around $2^{\circ} \mathrm{C}$ by $2050[31,32]$. This increase in temperature is sufficient enough to significantly affect the various life forms across the whole world.

There are three sectors that significantly contribute to the emission of GHGs via fossil fuel consumption: transportation, industry, and electric utilities [33,34]. Their contributions are graphically displayed in Figure 2 [35]. As indicated in Figure 2, major part of GHG-emissions has resulted from the fuel consumption in the transportation sector. Further, within the transportation sector, the light trucks and the cars that are used for private conveyance use significant proportion of the fossil fuels as shown in Figure 3 [36]. Also, it is evident from Figure 3 that disparity in the fuel consumption between private and heavy vehicles becomes substantial by the first quarter of this millennium. These data imply that considerable reduction of GHG-emission can be achieved only if the present energy sources used in the transportation sector are replaced by a cleaner and sustainable energy source, initially focusing the mediumsized vehicles.

A formal agreement to mitigate the GHG-emissions and safeguard the environment and human health is reflected in the Kyoto Protocol to the United Nations Framework Convention on Climate Change (FCCC) [37-39]. Under this agreement, the countries which ratify it are committed to reduce their GHG-emission or engage in emissions trading if they maintain or increase emissions of these gases. In addition to the aforementioned limitations, nonrenewable fuels have unfavorable energy efficiency when compared with the renewable energy sources. For instance, a conventional combustion-based power plant typically generates electricity 


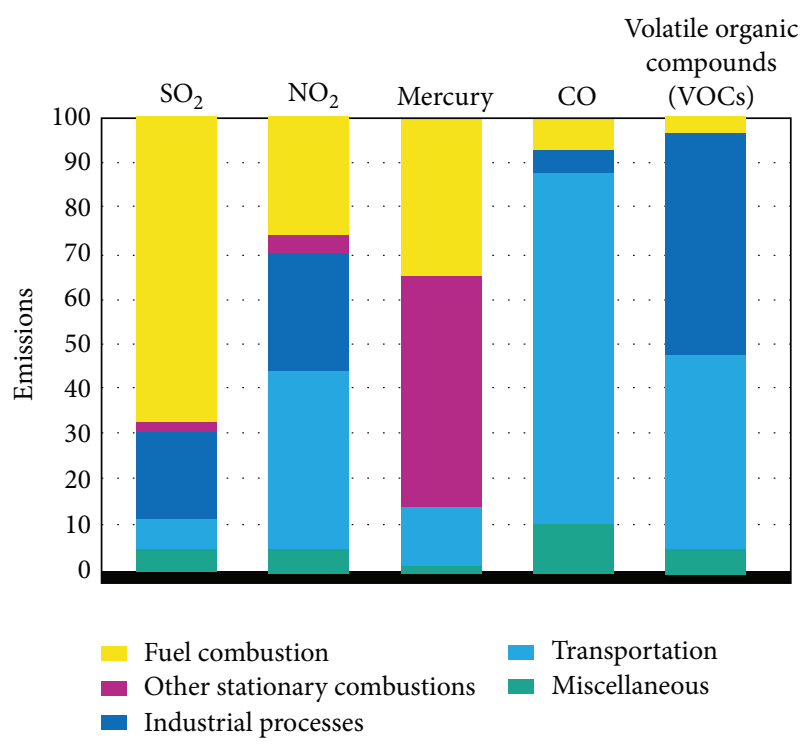

FIGURE 2: The contribution of various sectors to the emission of greenhouse gases in USA in million metric tons (MMT) and million metric tons of carbon equivalent (MMTCE) per year [35]. It can be seen that the transportation sector contributes significantly to increased emission of oxides of carbon and nitrogen and VOCs.

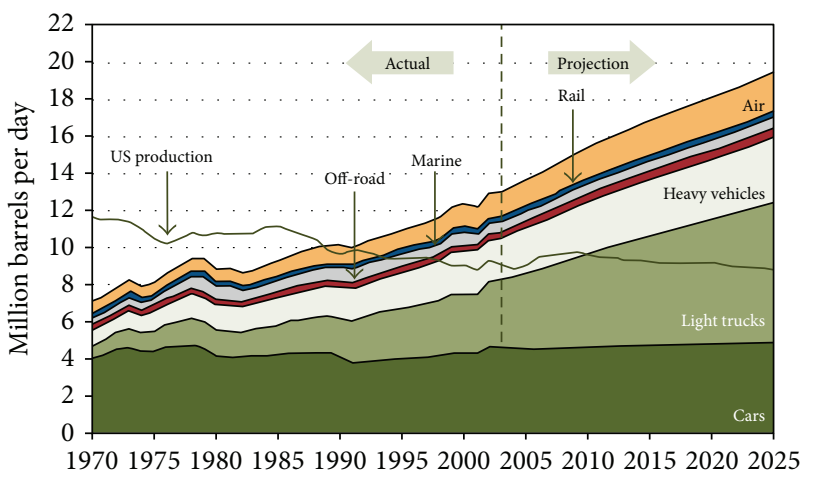

FIGURE 3: The relative proportions of fossil-fuel use in USA by different transportation modes projected to year 2025 [36]. It is evident that light trucks and cars that are predominantly used for private conveyance use considerable proportion of the fuels.

at efficiencies up to $35-42 \%$, while fuel plants that use renewable energy sources can reach efficiencies up to 70-90\% [40]. Likewise, the gasoline powered fuel cells can convert less than $30 \%$ of the energy into the power, while the fuel cells that are powered by renewable fuels such as hydrogen or methanol can utilize up to $60 \%$ of the fuel's energy $[41,42]$.

In short, considering the above three arguments, it can be seen that the transition from the present fossil-fuel based energy economy to a cleaner and sustainable energy economy will be driven by both economical and environmental reasons. The future of this implementation depends crucially on the energy storage technologies in combination with the generation of renewable energy sources. Hydrogen represents a primary renewable energy source which cannot

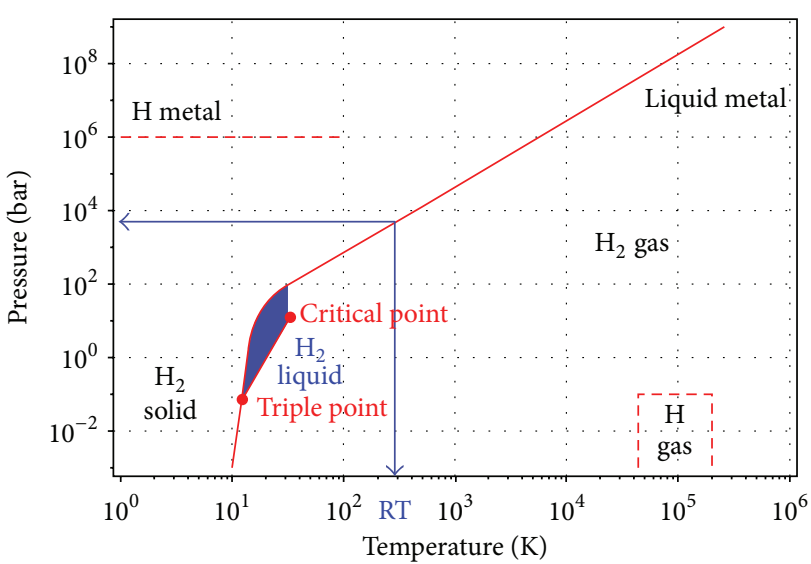

FIGURE 4: The primitive phase diagram of hydrogen. Figure adapted from [16].

be used directly but require intermediate conversion steps to maintain its improved attributes in terms of availability, supply, and safety. The challenges pertinent to the implementation of a hydrogen fuel based economy, in particular those associated with the high-density solid state hydrogen storage, are discussed in the following sections.

\section{Hydrogen Fuel Based Economy}

Hydrogen is a colorless, odorless, tasteless, and nonpoisonous gas. It is the most abundant element in the universe (75\% by mass), but it is not commonly found in the pure form, owing to the high reactivity. At the room temperature and atmospheric pressure, hydrogen exists as van der Waals gas with very low-density of $0.08988 \mathrm{~kg} / \mathrm{m}^{3}$ [43]. Hydrogen is a liquid in a small zone between triple and the critical points with a density $70.8 \mathrm{~kg} / \mathrm{m}^{3}$ at $-253^{\circ} \mathrm{C}$. At temperatures below $-262^{\circ} \mathrm{C}$, hydrogen exists as a solid with a density of $70.6 \mathrm{~kg} / \mathrm{m}^{3}$. Various physical phases of hydrogen are depicted in the primitive phase diagram in Figure 4 [16]. The energy characteristics of hydrogen as renewable fuel depend critically on its physical state of existence. Two important parameters that are extremely crucial for the transportation applications of hydrogen are the specific energy and the energy density. The former is the energy per unit mass of the fuel and is the measure of the net energy content of the fuel (measured in $\mathrm{kWh} / \mathrm{kg}$ ). This parameter decides the minimum refueling distance between two stoppages. The energy density of the fuel is the net usable energy/unit volume of the fuel (measured in $\mathrm{kWh} / \mathrm{m}^{3}$ ). The energy density of hydrogen decides the net system volume of the fuel storage system. At ambient pressure and temperature conditions, the energy density of hydrogen is nearly ten times lower than that of conventional fuels $[44,45]$. This low-energy density of hydrogen is a serious obstacle for the implementation of hydrogen fuel for automotive applications. In order to use hydrogen as a successful energy source in the transportation applications, its physical state has to be altered to improve its energy characteristics. 


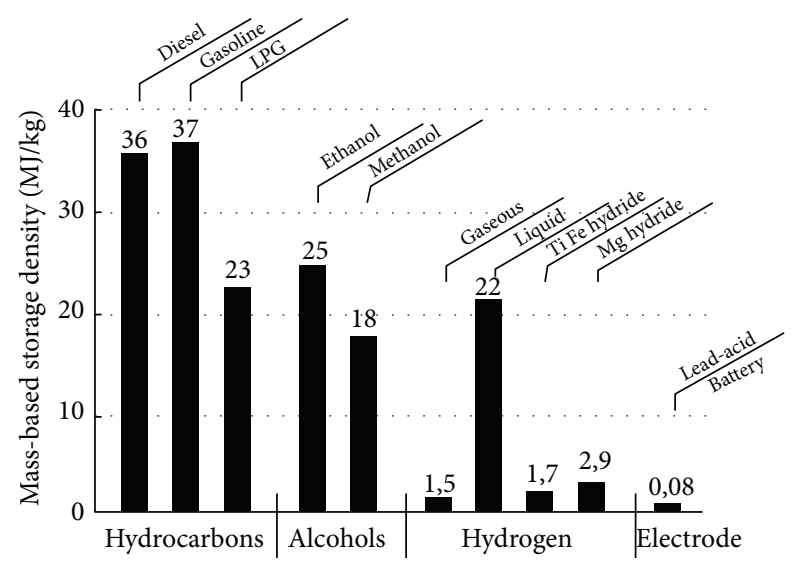

FIGURE 5: Specific energy of hydrogen compared with that of conventional fuels, based on the data from [44].

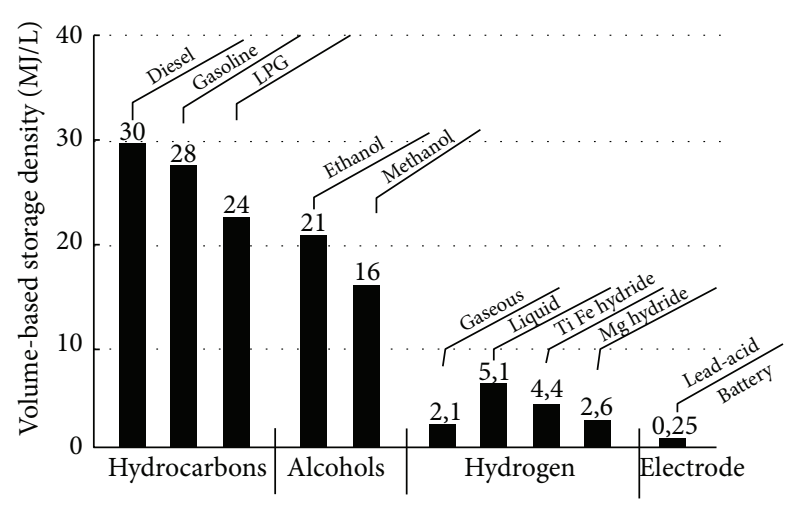

Figure 6: Energy density of hydrogen compared with that of conventional fuels, based on the data from [44].

\subsection{Comparison of Energy Characteristics of Hydrogen with} Conventional Fuels. For automotive applications, hydrogen has to meet and supercede the conventional fossil fuels in its energy characteristics. As mentioned previously, two most important parameters are the energy density and specific energy of hydrogen, which are, respectively, known as volume- and mass-based energy density [44, 45]. In Figures 5 and 6, a comparison of mass- and volume-based energy density of hydrogen with that of conventional fuels is made. It is evident from Figure 5 that even in its liquefied form hydrogen has nearly two times lesser energy density when compared with the gasoline.

A comparison of various properties of hydrogen and other conventional fuels relevant in the transportation sector is provided in Table 1 [46].

2.2. Benefits of Hydrogen Fuel Based Energy. A compilation of the salient positive attributes of hydrogen is provided in the following:

(a) Hydrogen is a nontoxic, clean energy carrier which does not produce carbon dioxide $\left(\mathrm{CO}_{2}\right)$, particulate, or sulfur emissions. However, it can produce oxides of nitrogen under some conditions. Its combinations with oxygen produces water and energy both are essential for the existence of life on earth.

(b) Hydrogen has a high specific energy on a mass basis when compared with any conventional fuels. Quantitatively, this can be understood by considering that the energy content of $9.5 \mathrm{~kg}$ of hydrogen is equivalent to that of $25 \mathrm{~kg}$ of gasoline [44].

(c) The energy density of hydrogen under ambient pressure and temperature conditions are lower as compared to the conventional fuels [44]. However, the volumetric energy density of hydrogen can be increased by storing hydrogen at lower temperatures or at higher pressures. Energy density of hydrogen can be improved also by adsorbing it into highly porous solid state materials.

(d) Hydrogen is highly inflammable. The energy that is required to ignite and burn hydrogen is nearly 10 times lesser when compared with that of conventional fossil fuels. Therefore, the automobiles that are equipped with hydrogen fuel do not have ignition problems even in most severe winter [47].

(e) Hydrogen has relatively high value for important transport properties such as kinematic viscosity, thermal conductivity, and diffusion coefficient, when compared with the conventional fuels. These together with its extremely low density and luminosity give it unique diffusive and heat transfer characteristics [47].

(f) Hydrogen can be produced via a multitude of processes. These include electrolysis of water, direct and indirect thermochemical decompositions, and processes driven directly by the sunlight. Additionally hydrogen can be produced via sequestration of hydrocarbon fossil fuels [48-50].

(g) Hydrogen can be safely transported in pipelines due to its high utilization safety.

(h) Hydrogen can also be used as a chemical feedstock in the petrochemical, food, microelectronics, ferrous and nonferrous metal, chemical and polymer synthesis, and metallurgical process industries.

(i) Compared to electricity, hydrogen can be stored over relatively long periods of time.

2.3. Transition of Present Energy Economy to a Hydrogen Fuel Based Economy. The cost of transition in the any energy delivering infrastructure involves investment of huge amounts of money [51]. Such a transition is considered irreversible and permanent step. It is estimated that the investment of the complete transition from the conventional petroleum based economy to the hydrogen based economy in USA alone will be millions of dollars [52]. The complete transition of the present day energy economy to a hydrogen-based energy economy implies the use of hydrogen as the main chemical energy carrier and the electricity as the main nonchemical form of energy. This transition is being made gradually and is likely to continue to the middle or the end of the 21st century. 
TABle 1: Properties of hydrogen compared to other fuels. Data adapted from [46].

\begin{tabular}{|c|c|c|c|c|c|c|c|}
\hline Property & Units & Hydrogen & Methane & Propane & Methanol & Ethanol & Gasoline \\
\hline Chemical formula & & $\mathrm{H}_{2}$ & $\mathrm{CH}_{4}$ & $\mathrm{C}_{3} \mathrm{H}_{8}$ & $\mathrm{CH}_{3} \mathrm{OH}$ & $\mathrm{C}_{2} \mathrm{H}_{5} \mathrm{OH}$ & $\mathrm{C}_{x} \mathrm{H}_{y}(x=4-12)$ \\
\hline Molecular weight $(\mathrm{a}, \mathrm{b})$ & & 2.02 & 16.04 & 44.1 & 32.04 & 46.07 & $100-105$ \\
\hline \multirow{2}{*}{ Density, NTP $(3, a, c)$} & $\mathrm{kg} / \mathrm{m}^{3}$ & 0.0838 & 0.668 & 1.87 & 791 & 789 & 751 \\
\hline & $\mathrm{lb} / \mathrm{ft}^{3}$ & 0.00523 & 0.0417 & 0.116 & 49.4 & 49.3 & 46.9 \\
\hline \multirow{2}{*}{ Viscosity, NTP $(3, a, b)$} & $\mathrm{g} / \mathrm{cm}-\mathrm{sec}$ & $8.81 E-5$ & $1.10 E-4$ & $8.012 E-5$ & $9.18 E-3$ & 0.0119 & $0.0037-0.0044$ \\
\hline & $\mathrm{lb} / \mathrm{ft}-\mathrm{sec}$ & $5.92 E-6$ & $7.41 E-6$ & $5.384 E-6$ & $6.17 E-4$ & $7.99 E-4$ & $2.486 E-4-2.957 E-4$ \\
\hline \multirow{2}{*}{ Normal boiling point $(\mathrm{a}, \mathrm{b})$} & ${ }^{\circ} \mathrm{C}$ & -253 & -162 & -42.1 & 64.5 & 78.5 & $27-225$ \\
\hline & ${ }^{\circ} \mathrm{F}$ & -423 & -259 & -43.8 & 148 & 173.3 & $80-437$ \\
\hline Vapor specific gravity, NTP $(3, a, d)$ & Air $=1$ & 0.0696 & 0.555 & 1.55 & N/A & N/A & 3.66 \\
\hline \multirow{2}{*}{ Flash point $(b, d)$} & ${ }^{\circ} \mathrm{C}$ & $<-253$ & -188 & -104 & 11 & 13 & -43 \\
\hline & ${ }^{\circ} \mathrm{F}$ & $<-423$ & -306 & -155 & 52 & 55 & -45 \\
\hline Flammability range in air $(c, b, d)$ & vol\% & $4.0-75.0$ & $5.0-15.0$ & $2.1-10.1$ & $6.7-36.0$ & $4.3-19.0$ & $1.4-7.6$ \\
\hline \multirow{2}{*}{ Autoignition temperature $(b, d)$} & ${ }^{\circ} \mathrm{C}$ & 585 & 540 & 490 & 385 & 423 & $230-480$ \\
\hline & ${ }^{\circ} \mathrm{F}$ & 1085 & 1003 & 914 & 723 & 793 & $450-900$ \\
\hline \multirow{2}{*}{ Maximum flame velocity in air $(2, c)$} & $\mathrm{m} / \mathrm{s}$ & 2.83 & 0.45 & 0.46 & $\mathrm{~N} / \mathrm{A}$ & $\mathrm{N} / \mathrm{A}$ & N/A \\
\hline & $\mathrm{ft} / \mathrm{s}$ & 9.28 & 1.48 & 1.52 & & & \\
\hline
\end{tabular}

A pragmatic and quantitative assessment of this transition can be made by following the production trend of hydrogen. The current world production of hydrogen is nearly 50 million tons/year, which is equivalent to approximately $2 \%$ of the world energy demand $[53,54]$. In order to expand the role of hydrogen in the near future, several approaches are being proposed. One of them is to use hydrogen for transportation by mixing it with the natural gas as fuel for internal combustion engines (ICEs). This increases the engine performance and decreases the pollution [55, 56]. Another approach involves producing hydrogen at central locations and distributing it to refilling stations, where it can be used in the liquid form in the fuel cell powered light motor vehicles. The gradual takeover of the hydrogen fuel based economy will involve several phases and is likely to be introduced over a long period of time. The following time-bound phases can be identified in the process of this takeover [57]:

(a) In the near term, the hydrogen will be produced primarily via the advanced steam reforming of natural gas. This process is a well-understood one and cost of the process depends mainly on the feedstock investment [48]. Steam reforming can be performed at the central locations or at the distributed facilities. The steam reforming of natural gas decreases the amount of $\mathrm{CO}_{2}$ released into the atmosphere, since the byproduct of steam reforming is high-purity $\mathrm{CO}_{2}$ which can be collected and used in many ways.

(b) In the medium term, the restructuring of the electric utility industry can be performed. This will give opportunities for the distribution generation of hydrogen fuel. In this term, the on-site generation of electricity will be carried out by hydrogen powered fuel cells. In addition to electricity, the fuel cells also produce thermal energy for hot water and space heating. In this phase, hydrogen required can be increasingly produced from coal and from the gasification of dedicated biomass.

(c) In the final phase of establishing the hydrogen fuel based economy, strong hydrogen markets and growing hydrogen infrastructure can establish opportunities for complete renewable hydrogen systems. The hydrogen required for the fuel cells can be produced via the electrolysis of water using intermittent energy technologies such as wind turbines and photovoltaic systems [57]. Fuel cells will use hydrogen to generate electricity during high-demand periods or to supplement the intermittent energy sources. The emergence and growth of advance technologies that produce hydrogen from water and sunlight and the technologies that store hydrogen in high-energy density systems will likely to take place during this phase. Commercialization and market penetration of advanced technologies to produce, store, and use hydrogen in the final phase will mark the establishment of hydrogen energy economy.

The establishment of hydrogen based economy, however, suffers from some uncertainties, mostly associated with the technologies that deal with its infrastructure [57]. For instance, the hydrogen economy is envisaged as the end state based on hydrogen produced from renewable power sources such as solar energy or wind energy. However, it is not yet economic to produce hydrogen in these ways. Secondly, hydrogen powered fuels provide clean and efficient energy for future vehicles and stationary power generation which is meaningful only if the hydrogen is produced cleanly. Further, the cost and technical hurdles associated with mass adoption of fuel cells need to be addressed. Also, there are 


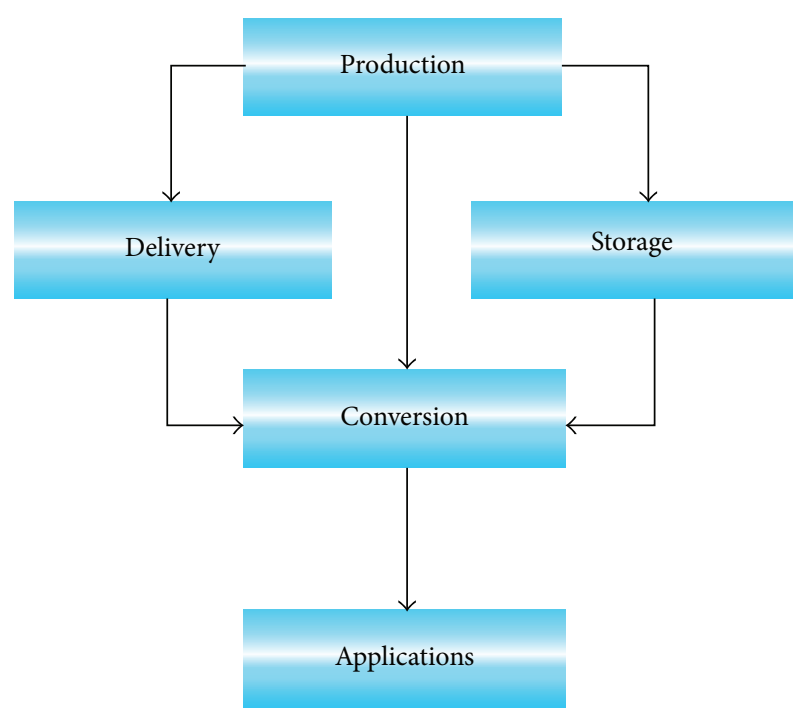

FIGURE 7: Schematic representation of various elements involved in the establishment of hydrogen fuel infrastructure.

uncertainties associated with the fuel cell cost and viability that can challenge its market penetration [58].

2.4. Elements of a Hydrogen Energy Infrastructure. In spite of various compelling benefits of hydrogen fuel based economy, its realization faces multiple challenges. This is because, unlike the conventional fuels, hydrogen has no existing largescale supporting infrastructures. Consequently, implementing an economy completely based on hydrogen requires development of various hydrogen energy infrastructures. Further, it is necessary to establish close coordination and integration of these elements. The main elements of a hydrogen energy infrastructure are the ones related to its production, delivery, storage, conversion, and applications. A schematic representation of these elements and their interrelationship is provided in Figure 7 [57].

In the following, these elements, their present status, and the technical challenges are discussed.

(a) Production of Hydrogen. For the establishment of hydrogen as the primary source of energy, it needs to be produced centrally in large refineries, energy complexes, or renewable or nuclear power stations. It can also be produced locally in power plants, fueling stations, communities, rural areas, and on-site customer's premises. Bulk of the present hydrogen production is performed via the catalyzed steam reformation of natural gas. Though this process is considered to be the cheapest option presently available, the cost factors are not favorable for large-scale commercialization for onboard hydrogen supply $[59,60]$. This is particularly true when the costs of hydrogen production technologies are compared with that of conventional fuels [14]. Another factor that hinders the advancement of hydrogen production technologies is the low demand for the hydrogen. Also, present sequestration techniques produce large quantities of greenhouse gases and the processes are not optimized for the reduction or environmentally sound carbon capture [61]. Three other major technologies for the hydrogen production currently under consideration are the electrolytic hydrogen production from alkaline, polymer membrane, and ceramic oxide electrolytes [62]. The key challenges associated with the production of hydrogen are the alternative low-cost production techniques for hydrogen from renewable fuels, dedicated biomass and nuclear sources, and environmentally sound carbon capture techniques for existing sequestration methods [63].

(b) Delivery. The second component of the hydrogen energy infrastructure is the delivery of hydrogen, which involves the transport of hydrogen from its productions site to the end-user device. Most of the hydrogen produced is currently transported by road via cylinders or cryogenic tankers. Delivery via pipelines is also a prevailing method of hydrogen delivery $[64,65]$. In high-demand areas, pipelines can be used to distribute hydrogen. To distribute hydrogen to rural and other lower-demand areas, trucks and other transportation means need to be used. This hydrogen can be gaseous, liquid, or solid hydrogen carriers. In order to advance the delivery of hydrogen, low-cost hydrogen transport technology must be identified and developed. Further, an advanced supply network should accommodate both centralized and decentralized hydrogen production facilities.

(c) Storage of Hydrogen. One of the most important challenges in the implementation of hydrogen based energy is finding an appropriate storage medium for hydrogen [11]. This is particularly true for mobile applications of hydrogen fuel. This can be illustrated by considering the large volume occupied by hydrogen at room temperature and moderate pressures. For realistic driving distances, typically $4 \mathrm{~kg}$ of hydrogen is required, which occupies nearly $50 \mathrm{~m}^{3}$ at ambient pressures and temperature conditions [11]. This large container size adversely affects the vehicle size. Thus, to store hydrogen in any useful form, it must be altered to achieve a higher energy density. The energy density target for a successful hydrogen storage medium, specified by the partnership between US DOE and FreedomCAR, is $1.2 \mathrm{kWh} / \mathrm{L}$ [66]. The energy density of hydrogen in its various forms is depicted in Figure 8 [36]. It is evident from the figure that only liquefied hydrogen has the above energy density $1.2 \mathrm{kWh} / \mathrm{L}$, which presently qualifies as a motor fuel [67]. However, it is not economical to store hydrogen in the liquid form because it is an energy intensive process [68]. In addition, liquid hydrogen storage suffers from fuel-loss due to the boil-off $[69,70]$. Due to extremely high kinematic transport parameters and low ignition threshold, minor leakage of hydrogen can be huge safety threats [71]. Additionally, this form of storage suffers problem related to safety $[47,71]$. The problems in the onboard hydrogen storage can be circumvented only if relatively lightweight, low-cost solid state hydrogen storage devices are identified and developed. Additionally, they should have high storage density as required by the FreedomCAR targets. Ongoing research to identify novel materials for hydrogen storage suggests that nanoporous materials, such as carbon nanotubes, metal-doped carbon nanotubes, metal-organic 


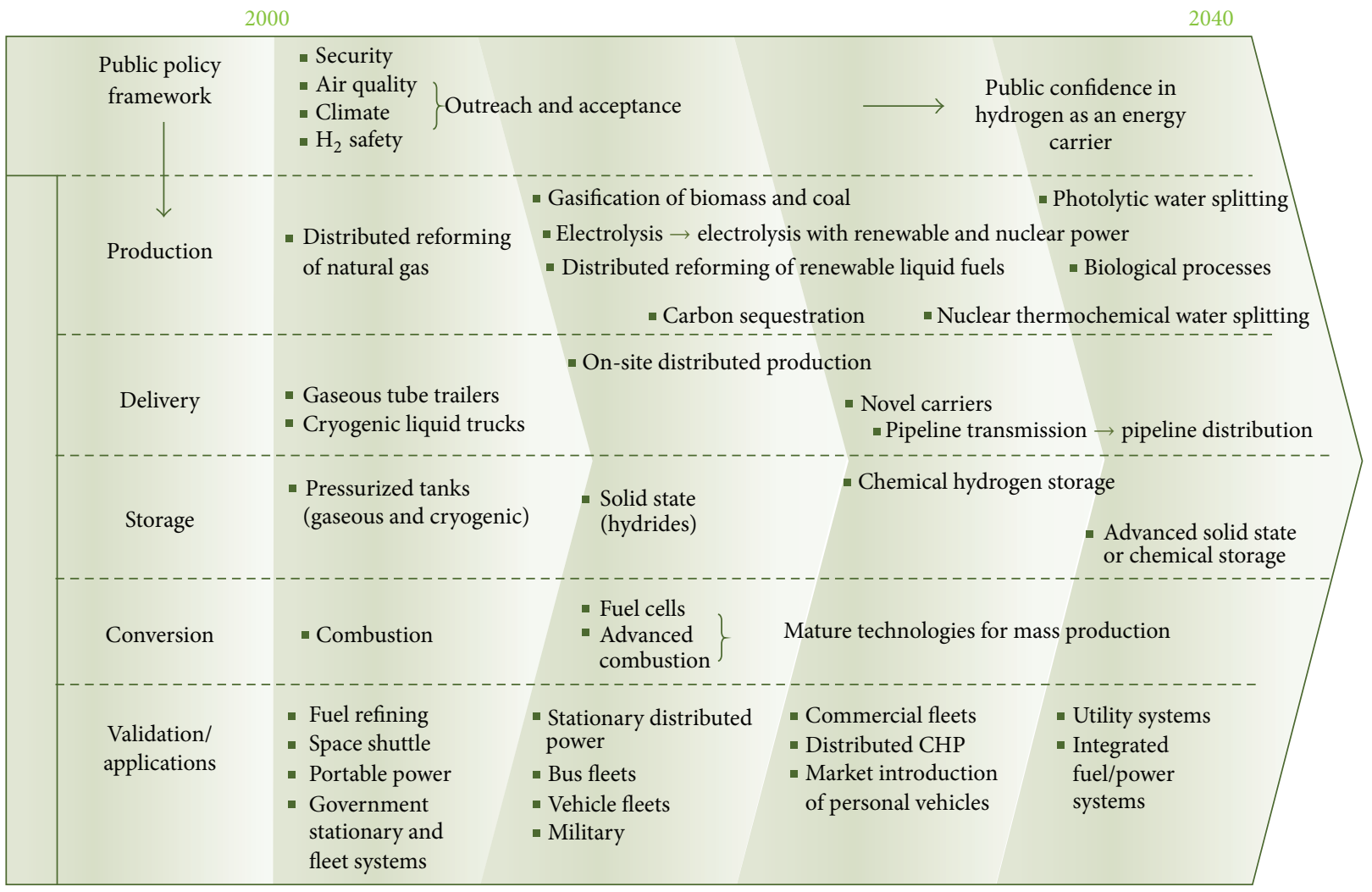

FIGURE 8: The present status of various elements of hydrogen energy infrastructure. The predicted mature technologies by the end of 2040 , envisioned by United States Department of Energy, are indicated on the right side [36].

frameworks (MOFs), covalent-organic frameworks (COFs), complex chemical hydrides, clathrates, and intermetallic alloys, are the most promising materials for future hydrogen storage [16-19].

(d) Conversion. The conversion of hydrogen fuel into energy can be accomplished in either an internal combustion engine or fuel cells. The former produces energy by burning hydrogen in the presence of oxygen, while the latter use the chemical energy of hydrogen molecules. Combustion method comprises two technologies: gas turbines and reciprocating engines [57]. At present, the hydrogen fuel based gas turbines are exclusively used in aviation industry [72, 73]. The latter techniques, that is, the use of fuel cells to generate energy from hydrogen, are envisaged as attractive alternative to combustion-based engines due to formers higher efficiency [74]. Consequently, the maturing of hydrogen based energy system depends on cost-competitive mass production of fuel cells $[58,75]$. This is hindered as none of the present fuel cell technology has met all criteria for performance, durability, and cost [58]. Additionally, standalone conversion devices such as combustion turbines and reciprocating engines need to be developed to off-board applications.

(e) Applications. In the application sector, hydrogen should be available for every end-user energy need in the economy. This includes the onboard applications, such as transportation and mobile utility systems, and stationary applications, such as central and distributed electric power and combined heat and power for buildings and industrial processes. For short terms, the most important sector that will be using hydrogen will be the transportation sector. For mobile applications hydrogen-based fuel cell is the most appealing option. Most of the major automobile makers presently have hydrogenfueled vehicle programs [76]. The acceptance of the hydrogen fueled vehicles for end-user applications can be enhanced by performing successful field tests and demonstrations. Additionally, supportive public policies should be developed to stimulate the acceptance of infrastructure and market readiness. For stationary applications, combustion-based process, such as gas turbines and reciprocating engines, can be designed to use hydrogen.

(f) Codes, Standards, and Education. The final element in the implementation of hydrogen energy infrastructure is the codes and standards. Families of model building codes should be available for adoption. These deal with comprehensive references to equipment standards for both hydrogen and fuel cell technologies for the commercial and residential applications. In addition, published safety standard for the certification of fuel cell vehicles and published fuel gas code should be available. Increased public awareness on the benefits and merits of hydrogen economy can be highlighted by education and outreach programs. It is also important to establish regional, local, and national networks that commit resources for long-term education of students at all levels. Such training 
and certification program finally intensify the acceptance of the hydrogen based storage and application devices.

A schematic relation of the various hydrogen energy infrastructures is envisaged by the Department of Energy, USA (Figure 8). This incorporates the present status and the expected matured technology by the year 2040 [36].

\section{Hydrogen Storage: Targets and Opportunities}

The establishment of a hydrogen fuel in the transportation applications depends largely on the availability of novel hydrogen storage media that satisfies a set of selection criteria. This includes parameters, such as high hydrogen content per unit mass and unit volume, limited energy loss during operation, fast kinetics during charging, low self-discharge during stoppage, high stability with cycling, cost of recycling and charging infrastructures, and safety concerns in regular service or accidents. The technical limits of above parameters depend on the region of operation and are proposed by agencies, such as Department of Energy (DOEs, US) [DOE], world energy network (WE-NET, Japan) [WENET], and International Energy Agency (IEA) [IEA].

3.1. Targets to Be Met and Their Explanations. The technical targets of a hydrogen storage medium that can be successfully used for mobile applications are time-bound and the upper limit in the energy characteristics of a storage medium is proposed by the partnership between US DOE and FreedomCAR [36]. Amongst several parameters mentioned above, the most significant ones are the gravimetric storage capacity and the volumetric storage capacity. The respective DOE target for the year 2015 is $5.5 \mathrm{wt} \%$ and $40 \mathrm{~g} / \mathrm{L}$ at $233-$ $358 \mathrm{~K}$ and $3-100$ bars. The ultimate target set by the DOE is $7.5 \mathrm{wt} \%$ and $70 \mathrm{~g} / \mathrm{L}$ [77-80]. The targets are designed so as to enable a refueling distance of $500 \mathrm{~km}$ for light motor vehicles. Another important factor in selecting a storage medium is the safety associated with the system during its regular use and accidents. The storage techniques such as the liquefied hydrogen and compressed gas which are presently being used are high risk methods of hydrogen storage [81]. Another factor of central importance is the cost of the storage system. The proposed target for the cost of storage system is about $4 \$ / \mathrm{kWh}[82,83]$. Also, there are stringent requirements regarding the response time and maximum and minimum operating temperature at which hydrogen storage and release can be performed. The former (response time) controls the vehicle performance and proposed technical limit is $0.75 \mathrm{~s}$ [36]. In order to gain a complete acceptance for the transportation use, the storage system must track the needs of the fuel cell closely to provide the adequate power and a suitable driving experience. This asymmetric parameter affects the system performance, fuel cell durability, and vehicle stability. The acceptable maximum and minimum temperature conditions for the storage system are -40 and $85^{\circ} \mathrm{C}$, respectively. The temperature limit depends also on the working conditions of the fuel cells, which is presently $85^{\circ} \mathrm{C}$ $[70,80]$.
As mentioned previously, the most important challenge in storing hydrogen is achieving the specific energy density target of FreedomCAR. In order to do this, hydrogen needed to be compressed into a smaller volume. This can be accomplished using few methods. One method is to mechanically change the pressure and temperature so that the energy per unit volume of hydrogen increases [11]. This method currently being used in all hydrogen powered vehicles uses either compressed gaseous hydrogen or liquefied hydrogen [67]. Liquid hydrogen storage at low pressures and cryogenic temperature is light and compact. Also, it has high hydrogen content that satisfies both energy characteristics (Figure 6). However, it suffers a very high disadvantage that nearly $33 \%$ of overall energy content is lost during the liquefaction process [84]. Further, the evaporation during off-periods can only be partially reduced by recooling systems [76]. Both the compressed gaseous and the liquid hydrogen storage are considered as huge security risks due to potential explosions in case of accidents [77-80]. Other promising solid state materials for high-density hydrogen storage are metallic or intermetallic hydrides and complex chemical hydrides $[85,86]$. Additionally, the state-of-the-art methods of storing hydrogen in nanostructured materials such as carbon nanotubes, metal-doped carbon nanotubes, metal and covalentorganic frameworks (MOFs) and (COFs), and clathrate hydrates have gained increased attention. The latter two options will prove to be of larger importance to the portable fuel cell industry because energy density is a much more important consideration for portable systems when compared to the off-board applications. Next subsections of this review are dedicated to these novel solid state hydrogen storage techniques. Only if these methods obtain extremely high efficiency will they become realistic candidate for offboard scale energy storage.

In Figure 6, the specific energy (gravimetric capacity) and the energy density (volumetric capacity) of hydrogen in various physical states are provided [43]. From Figure 6, it is clear that only liquefied hydrogen exceeds the aforementioned criteria at present. As evident from Figure 6, any other forms of its storage, hydrogen possesses low volumetric energy density. This suggests that to store hydrogen in any useful form, even in the stationary context where the size of the storage is of smaller importance, it must be altered to achieve a higher energy density. This constitutes one of the big challenges in implementing the hydrogen fuel based economy.

3.2. Metals and Intermetallic Hydrides. Hydrogen reacts with many transition metals and metallic alloys at elevated temperatures to form hydrides $[87,88]$. Lanthanide, actinides, and the members of $\mathrm{Ti}$ and $\mathrm{V}$ groups are the most reactive transition elements that readily form the hydrides. The binary hydrides of transition metals are metallic in character and are commonly referred to as metallic hydrides. Their compositions are generally expressed as $\mathrm{MH}_{x}$, where $x$ can vary from ideal stoichiometry and forms multiphase systems depending on the pressure and temperature [89]. Most interesting metallic hydrides belong to intermetallic hydrides with 


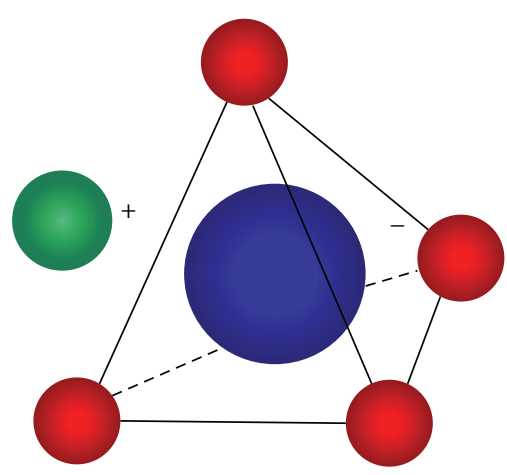

(a)

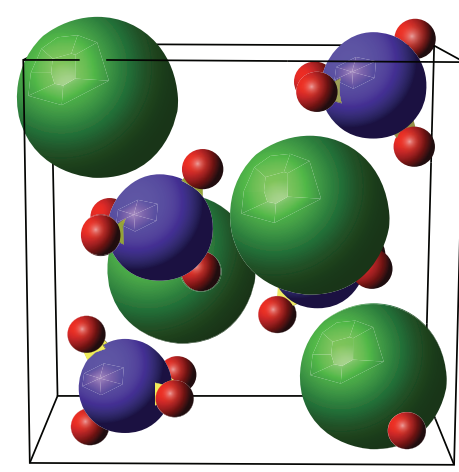

(b)

FIGURE 9: Molecular structure of $\mathrm{NaBH}_{4}$ (a). Sodium, boron, and hydrogen are represented by green, blue, and red spheres. (b) Showing the crystal structure of the same.

TABLE 2: The families of hydride forming intermetallic compounds, their prototypes, and structure, adapted from [16].

\begin{tabular}{lcc}
\hline $\begin{array}{l}\text { Intermetallic } \\
\text { compound }\end{array}$ & Prototype & Structure \\
\hline $\mathrm{AB}_{5}$ & $\mathrm{LaNi}_{5}$ & Haucke phase, hexagonal \\
$\mathrm{AB}_{2}$ & $\mathrm{ZrMn}_{2}$ & Laves phase, hexagonal, cubic \\
$\mathrm{AB}_{3}$ & $\mathrm{CeNi}_{3}$ & Hexagonal \\
$\mathrm{A}_{2} \mathrm{~B}_{7}$ & $\mathrm{Y}_{2} \mathrm{Ni}_{7}$ & Hexagonal \\
$\mathrm{A}_{6} \mathrm{~B}_{23}$ & $\mathrm{Y}_{6} \mathrm{Fe}_{23}$ & Cubic \\
$\mathrm{AB}$ & $\mathrm{TiFe}$ & Cubic \\
$\mathrm{A}_{2} \mathrm{~B}$ & $\mathrm{Mg}_{2} \mathrm{Ni}$ & Cubic \\
\hline
\end{tabular}

general composition of $\mathrm{AB}_{n} \mathrm{H}_{x}$. Here, element $\mathrm{A}$ is a rare earth or an alkaline earth metal and B is a transition metal. Since the hydriding and dehydriding properties of intermetallic hydride depend on the ratio of $\mathrm{A}$ and $\mathrm{B}$, it is possible to tailor these properties by appropriate selection of metals and their combinations. A typical example of intermetallic ternary system is $\mathrm{LaNiH}_{6}$, where $\mathrm{A}$ is the lanthanum and $\mathrm{B}$ is nickel. One of most attractive features of metallic hydrides is the extremely high volumetric density of hydrogen. $\mathrm{LaNi}_{5}$, for instance, can reach a volumetric hydrogen density of $115 \mathrm{~kg} / \mathrm{m}^{3}$ [16, 86]. In Table 2, most important families of hydride form intermetallic alloys and their prototype and respective structure are provided.

Metal hydrides are very effective in storing large amount of hydrogen in a safe and compact way. However, transition metal hydrides, those working reversibly at room temperature and moderate pressure, store a maximum of only $3 \mathrm{wt} \%$ of hydrogen (gravimetric storage capacity) [16, 86]. Therefore, the possibilities of lightweight metal hydrides which can reversibly store more than $5 \mathrm{wt} \%$ of hydrogen are needed to be explored.

3.3. Complex Chemical Hydrides. Lighter elements of groups 1, 2, and 3, such as $\mathrm{Li}, \mathrm{Mg}$, and B, have been found to form a series of complex hydrides which can be used a chemical method to store hydrogen $[85,90-92]$. They are particularly interesting for the mobile hydrogen storage application because of their low density and high hydrogen-to-metal ratio [90-92]. Unlike metallic hydrides the complex hydrides are ionic or covalent in character. Sodium borohydride $\left(\mathrm{NaBH}_{4}\right)$ is typical example of complex metal hydride. Most of complex metal hydrides have tetrahedral structure as seen in Figure 9(a) with hydrogen occupying the corners of the tetrahedron [91, 92]. Also these materials are stable compounds decomposing only above their melting points.

Complex chemical hydrides usually possess enormous gravimetric storage capacities $[91,92]$. The complete release of hydrogen from $\mathrm{LiBH}_{4}$ is equivalent to $45.5 \mathrm{wt} \%$ of hydrogen $[91,92]$. At room temperature, the amount of hydrogen released from $\mathrm{LiBH}_{4}$, for instance, is equivalent to $18.5 \mathrm{wt} \%$ [91, 92]. The challenge in utilizing these materials includes reducing their decomposition temperature. This high decomposition temperature is related to their stability which in turn is related to the percentage ionic character and steric effects. Therefore, to use these materials for mobile hydrogen storage, it is essential to find out the conditions under which their decomposition temperature can be reduced. In Figure 10, a comparison of the gravimetric and volumetric storage capacities of metal hydrides with the proposed 2010 and 2015 FreedomCAR target is provided [93]. A new set of 2020 and ultimate target of gravimetric and volumetric capacity for onboard fuel cell vehicles is $1.8 \mathrm{kWh} / \mathrm{kg}, 1.3 \mathrm{kWh} / \mathrm{L}$ and $2.5 \mathrm{kWh} / \mathrm{kg}, 2.3 \mathrm{kWh} / \mathrm{L}$ [94].

3.4. Nanostructured Carbon Materials. Amongst all emerging materials for the solid state hydrogen storage, nanostructure carbon materials, especially carbon nanotubes (CNTs) and carbon nanofibers (CNFs), received the most attention. Also, the hydrogen storage in carbon nanotubes is probably the single most controversial topic as far as the solid state hydrogen storage is concerned [95]. Single-wall carbon nanotubes (SWCNTs) can be assumed to form by rolling a single graphene sheet [96]. Owing to several unique properties of CNTs, they are envisaged as a very good medium for solid state hydrogen storage. For instance, they are typically inert to 


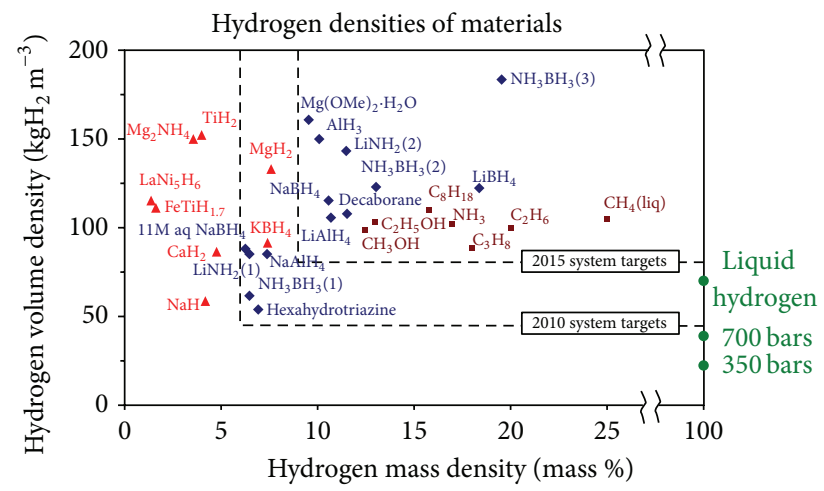

FIGURE 10: A comparison of hydrogen volumetric and gravimetric densities of complex metal hydrides with that of proposed 2010 and 2015 FreedomCAR targets [93].

surface contaminants and therefore less severe activation conditions are only required. Also, in SWCNTs, all carbon atoms are exposed to the surface. This makes them the material with highest surface-to-bulk atom ratio and therefore highly surface active. The densities of CNTs are considerably lower than that of metals, intermetallic alloys, COFs, and MOFs. Also, these nanomaterials are known to possess large amount of void spaces in the form of pores which can accommodate large quantities of hydrogen. Hydrogen can be physisorbed in SWCNT bundles on various sites such as external wall surface, grooves, and interstitial channels [97]. Therefore, it can also have large energy density as required for the mobile applications. It is also found that by tuning the adsorption conditions hydrogen can be either chemisorbed or physisorbed on carbon nanotubes.

The studies on the hydrogen storage properties of carbon nanotubes were triggered after the pioneering work by Dillon et al. [98]. They reported a gravimetric storage capacity between 10 and $20 \mathrm{wt} \%$. The experiments on hydrogen adsorption in CNTs can be broadly divided into two, depending on the method of storage: gas-phase hydrogen storage and electrochemical hydrogen storage [95]. In gas-phase hydrogen storage techniques, a macroscopic sample of nanotubes, typically weighing less than $1 \mathrm{~g}$, is exposed to pure hydrogen gas under various temperature and equilibrium pressure conditions. The amount of hydrogen adsorbed by nanotubes is then measured gravimetrically using microbalance [99]. A more popular method of determining the amount of stored hydrogen is by volumetrically using Sieverts type volumetric apparatus [100]. The latter technique involves the exposure of carbon nanotubes to hydrogen gas in a known volume and determining the storage capacity from the change in the free volume of the system upon exposure. With smaller quantities of sample, the gravimetric storage capacities can also be determined using temperature programmed desorption (TPD) or thermogravimetric analysis (TGA) [101]. The second method of storing hydrogen in carbon nanotubes is electrochemical. To do this, an electrochemical cell is constructed with CNTs as the working electrode, $\mathrm{Pt}$ as the counter electrode, and an appropriate electrolyte [102]. In such a system, hydrogen is stored in the CNT electrode by the reduction of water at a suitable potential [102].

The earliest experiments on hydrogen storage capacity of CNTs performed by Dillon's group obtained 10-20 wt\% of capacity. In their study, they assumed that only CNTs contribute to the gas adsorption. Due to a very dilute CNT mixture they used the large mass correction (99.8\% of mass) of the material introduced considerable error into their storage capacity [98]. The volumetric measurement of the CNT-hydrogen storage capacity was initially performed by Ye et al. in 1999 [100]. The experiment performed using a Sieverts type volumetric instrument suggested that, at cryogenic temperatures and an equilibrium pressure of 120 bars, SWCNTs store nearly $8.5 \mathrm{wt} \%$. Hydrogen was stored in CNT electrochemically for the first time by Nützenadel et al. [103]. They found that storage equivalent of a discharge capacity of $110 \mathrm{mAh} / \mathrm{g}$ can be obtained when hydrogen is stored electrochemically. Though pristine-carbon nanotubes exhibit remarkable hydrogen storage capacity at cryogenic temperatures, its storage capacity diminishes to less than $1.0 \mathrm{wt} \%$ at room temperature [95].

It is worth noticing that, quite recently, there have been some efforts to tailor the surface characteristics of pristine nanotubes so as to increase their hydrogen storage capacities $[104,105]$. These surface modifications include high-energy atomic bombardment, reactive ball milling, high temperature annealing, and doping with transition metals [104-108]. Both high-energy atomic bombardment and reactive ball billing result in partial destruction of carbon nanotube structure by creating high density of defects [106-108]. These defect sites serve as additional hydrogen binding sites and up to $X$ wt $\%$ of hydrogen can be stored in defect enriched carbon nanotubes [107]. However, here hydrogen binds irreversibly via chemisorption and therefore, to release the stored hydrogen, the samples are required to heat over $500^{\circ} \mathrm{C}$ [109].

3.5. Metal-Doped Nanostructured Carbon Materials. The enhanced hydrogen storage properties of transition metaldoped carbon nanotubes have gained wide attention recently $[19,110-113]$. The transition metals that are typically used for doping CNTs are the ones which form hydride at ambient conditions including palladium, platinum, and vanadium [110] and are doped by incipient wetness or electron-beam evaporation technique [113-116]. The transition metal doping is found to increase the hydrogen storage capacity of CNTs by around $30 \%$ without adversely affecting the fast desorption kinetics $[19,110]$. The enhanced hydrogen storage capacities of doped nanotubes are explained using the spillover phenomenon, where hydrogen molecules were initially adsorbed by the transition metal particles and were subsequently spilled onto different adsorption sites of carbon nanotubes (see the schematic of spillover phenomenon in Figure 11) $[111,112,116]$. Readsorption data of Pd- and V-doped CNTs have indicated that more than $70 \%$ of hydrogen is spilled onto the low-energy binding sites such as external wall or groove sites of nanotubes $[19,110]$. These sites are associated with considerable low desorption barrier $\left(\sim k_{B} T\right)$ and therefore 


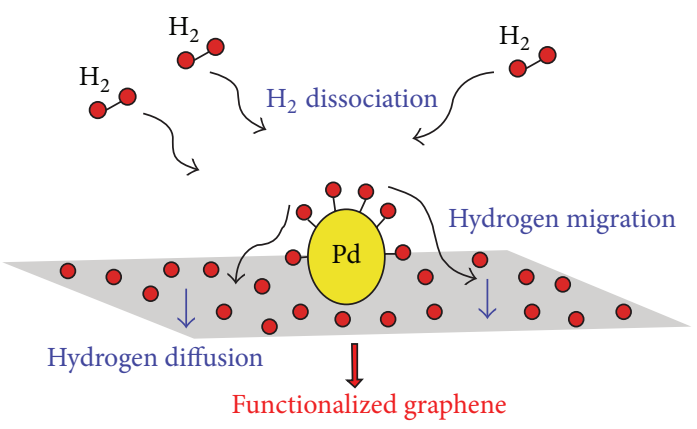

FIGURE 11: A schematic representation of the spillover phenomenon.

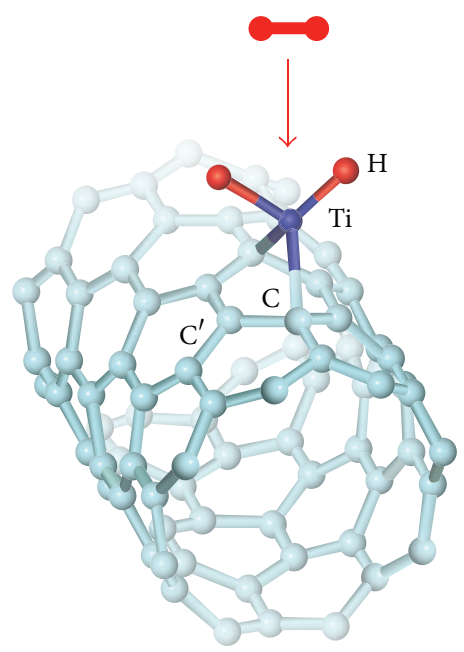

(a)

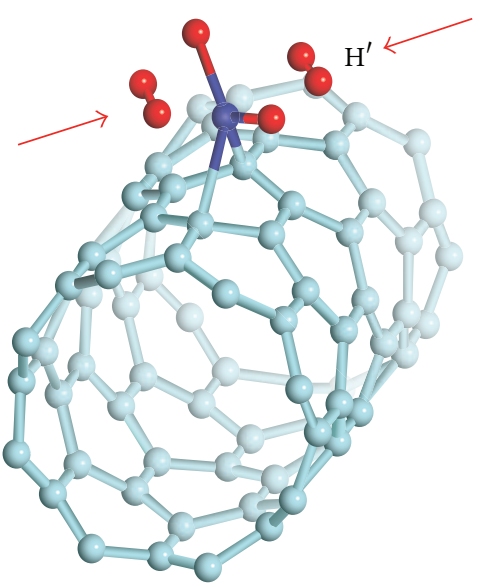

(b)

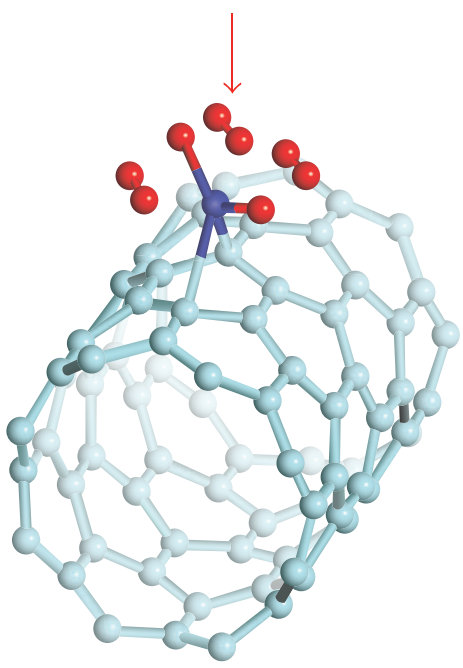

(c)

FIGURE 12: The configurations of hydrogen on Ti-doped carbon nanotubes [117].

explain why the doping does not affect the observed kinetics of desorption.

Hydrogen storage behavior of Ti-doped CNTs was predicted using first principle calculations [117]. Each Ti atom in the doped CNT can bind up to four hydrogen molecules which is equivalent to a gravimetric storage capacity of $8.0 \mathrm{wt} \%$ (Figure 12).

The bonding of hydrogen molecules in Ti-doped CNTs occurs via stepwise processes as indicated in Figure 12. In the first step, a hydrogen molecule undergoes dissociative chemisorption and binds to a single titanium atom (Figure 12(a)). Remarkably, this occurs without an energy barrier. In the second step, two hydrogen molecules are physisorbed as shown in Figure 12(b). In the final configuration, the fourth hydrogen molecule is physisorbed to $\mathrm{Ti}$ atom in a direction parallel to C-Ti plane (Figure 12(c)). This unexpected bonding is explained using unique hybridization between Ti- $d$, hydrogen $\sigma^{*}$ antibonding, and SWCNT C-p orbitals [117]. The experimental studies of the hydrogen storage remain as a controversial topic due to the large disparity in the storage capacities measured in various experiments [118]. This is primarily associated with the uncertainties in the sample purity used in various experiments. It is generally understood that CNTs contain some amount of metallic impurities, which are incorporated during their synthesis [119]. These metallic impurities adsorb hydrogen; therefore the unknown hydrogen storage contributions of metals are sometimes wrongly assigned to the storage capacity of nanotubes.

Other complications arise due to erroneous measurements, typically observed, in the case of volumetric determination of storage capacity [120]. The samples are exposed to hydrogen gas in a constant volume setup. For this type of study, the accurate dead volume of the instruments should be known. Though the precise volume of each of the components is known prior to the experiments, there will be some uncertainty in the total volume of the system when the components are fixed together. This uncertainty is not accounted for in many volumetric studies and constitutes some error in the measured capacity. Another factor that leads to erroneous measurement is the change in the storage capacity due to the change in the ambient temperature, during the experiment [95]. For an adsorption experiment performed at room temperature and $10 \mathrm{MPa}$ pressure, each degree change in the ambient temperature results in $33 \mathrm{kPa}$ of pressure which is equivalent to a storage capacity of 


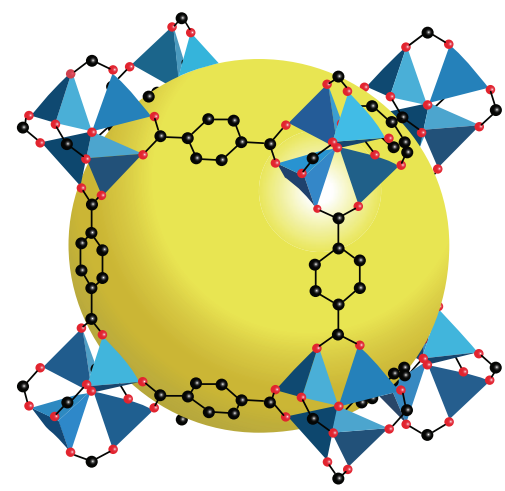

(a)

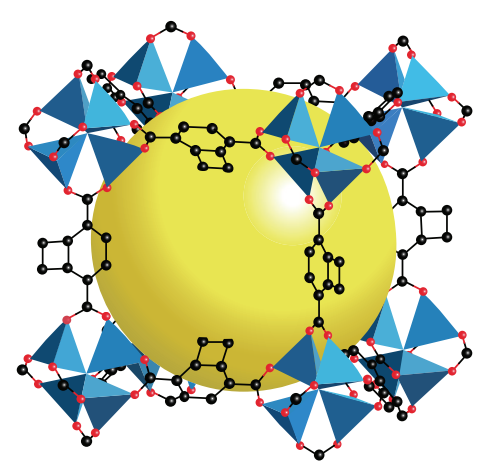

(b)

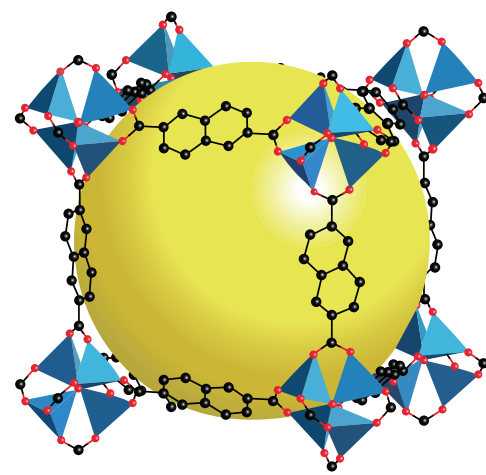

(c)

FIGURE 13: Single crystal X-ray structure of MOF-5 (a), IRMOF-6 (b), and IRMOF-8 (c) on each of the eight corners is a cluster of tetrahedral $\left[\mathrm{OZn}_{4}\left(\mathrm{CO}_{2}\right)_{6}\right]$. The large yellow sphere represents the largest sphere that would fit into the cavities without touching the van der Waals atoms of the frameworks [17].

$2.6 \mathrm{wt} \%$ [95]. This becomes very crucial for the measurements involving very small amount of nanotubes. Thus, it is vital to keep the experimental setup strictly in isothermal conditions. Additionally errors due to temperature fluctuation due to the expansion of the hydrogen gas and leaks in system affect the reliable measurement of gravimetric storage capacity [95]. Therefore, accurate, consistent, and reliable hydrogen storage data are obtained only if necessary precautions are taken during the storage experiments.

3.6. Metal-Organic Frameworks (MOFs). Metal-organic frameworks (MOFs) also known as porous crystalline coordination polymers formed by metallic polyhedra and organic molecules [121-123]. Inorganic building units, metal ions or clusters, and organic units carboxylates or other organic anions such as phosphonate, sulfonate, and heterocyclic compounds are linked together to form MOFs. Structure of MOFs is dependent on connectivity and geometry of organic linkers [124]. These frameworks have large cubic cavities of uniform sizes. Different structures of cavities formed in MOFs make them highly porous material. BET surface area of MOFs is quite high as compared to CNT, hydrides, zeolites, and clathrates and PCN-521 is considered as the most porous MOF among all the MOFs formed from tetrahedral linkers [124]. Some typical examples of MOFs are MOF-5, IRMOF-6, IRMOF-8, and so forth shown in Figure 13. The synthesis method for MOFs is simple, inexpensive, and straight forward. For instance, the MOF-5 can be synthesized from an alkaline zinc solution and 1,4-benzene dicarboxylic acid [125]. Different routes of synthesis method such as conventional heating, electrochemistry, microwave-assisted heating, mechanochemistry, and sonochemistry are used to prepare variety of MOFs $[17,126]$.

Microporous, open metal sites, high surface area, chemically tunable structures, and different types of cavities of MOFs labelled them as most promising candidate for hydrogen storage material [127, 128]. Hydrogen sorption behavior of MOFs indicates that they reversibly store hydrogen at ambient temperature and moderate pressures [129].
The typical storage capacity of MOF- 5 under aforementioned conditions is $1.0 \mathrm{wt} \%$. The storage capacity of the MOFs can easily be increased by introducing larger organic moieties into the frameworks. Maximum hydrogen storage capacity at room temperature of different kinds of microporous MOFs by varying organic linkers and metal sites reaches up to $1.65 \mathrm{wt} \%$ and hydrogen pressure 48 bars [17]. Hydrogen binding sites of MOFs are obtained from the neutron diffraction data [130]. The superimposition of the scattering intensity with molecular structure indicates the cup sites (green-yellow-red regions in the left panel of Figure 14), where hydrogen molecules are attached. Covalent-organic frameworks (COFs) are crystalline, highly porous, and large surface area. COFs possess the same properties like MOFs such as structure rigidity, surface area, pore volume, and different kinds of cavities but have low density due to the presence of $\mathrm{C}, \mathrm{Si}, \mathrm{B}$, and $\mathrm{O}$ as main clusters with organic unit carboxylates. Recently COFs are also emerging as the promising candidate for the hydrogen storage material due to the above-mentioned properties [131133].

3.7. Metal-Doped Metal-Organic Frameworks (MOFs). Hydrogen storage capacity in pristine MOFs at room temperature is nowhere near the ultimate target $(7.5 \mathrm{wt} \%$ and $70 \mathrm{~g} / \mathrm{L})$ set by the Department of Energy (DOE) for onboard hydrogen storage systems [128]. However, at $77 \mathrm{~K}, \mathrm{MOF}$ show very high hydrogen storage capacity which reaches close to the ultimate US DOE hydrogen storage target for vehicular applications; but for practical onboard hydrogen storage purposes, $77 \mathrm{~K}$ is not feasible. Recently different kinds of routes were implemented to enhance hydrogen storage capacity in MOFs at room temperature and one of the methods is doping. Different kinds of metals with and without support (carbon materials) were doped into microporous MOFs [134-137]. Different techniques of metal doping into MOFs were used; the most common is incipient wetness and ball milling method [135, 137, 138]. Liu et al. reported that hydrogen uptake capacity of microporous 


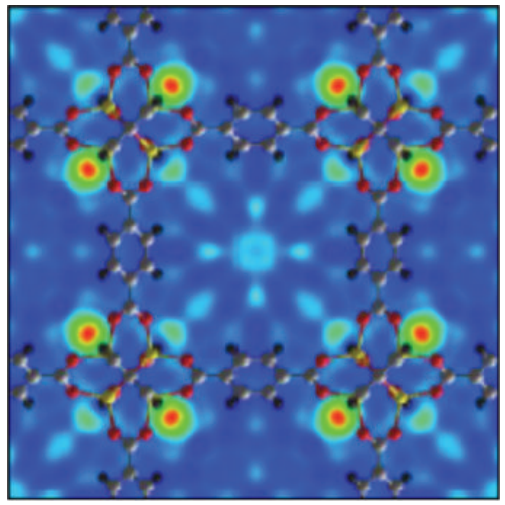

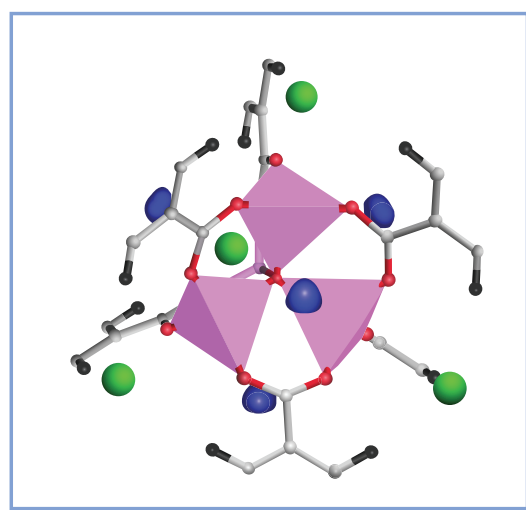

(a)

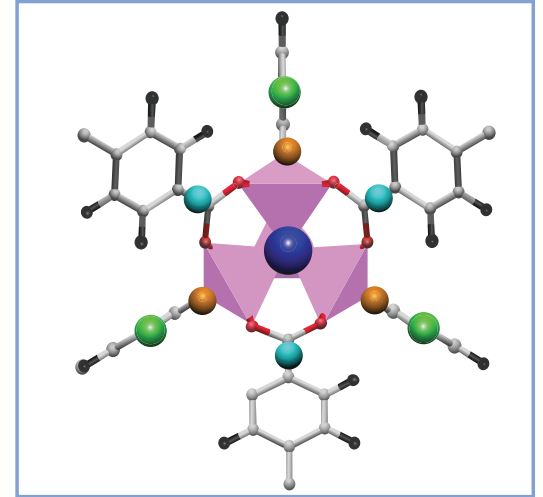

(b)

FIGURE 14: The super position of scattering intensity from neutron diffraction data with molecular structure of MOF-5 suggests the binding sites [130].

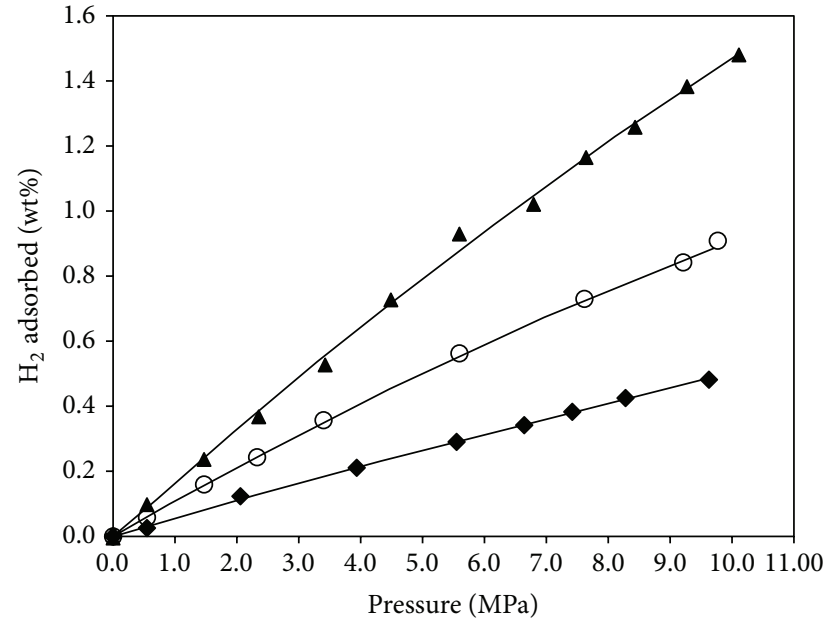

FIGURE 15: Hydrogen storage capacity of MIL-101, Pt/C-MIL-101, and MIL-101-bridges-Pt/C at $298 \mathrm{~K}$ [139].

CuBTC was increased 3.5-fold at $298 \mathrm{~K}$ and 20 bars by addition of Pt/C catalyst [135]. Furthermore, structural integrity was maintained upon mixing catalyst with CuBTC. Spillover mechanism in metal-doped MOFs is a promising method to increase the hydrogen storage capacity at RT. In addition, by introducing carbon with the metal into MOFs, carbon acts as a bridge between the source and receptor. Building bridging by carbon with metal in MOFs enhances the hydrogen storage capacity remarkably [139-141]. Comparison of hydrogen uptake capacity of pure MIL-101 with doped MIL-101 via spillover mechanism and bridging is shown in Figure 15 [139].

3.8. Clathrate Hydrates. Clathrates are crystalline molecular complexes formed from the mixtures of host molecules and suitably sized gas molecules [142]. They are known also as caged compounds, since in these systems guest molecules are occluded in the cages formed by the host molecules. When the cages are formed by the water molecules, clathrates are known clathrate hydrate. The structure II consists of two

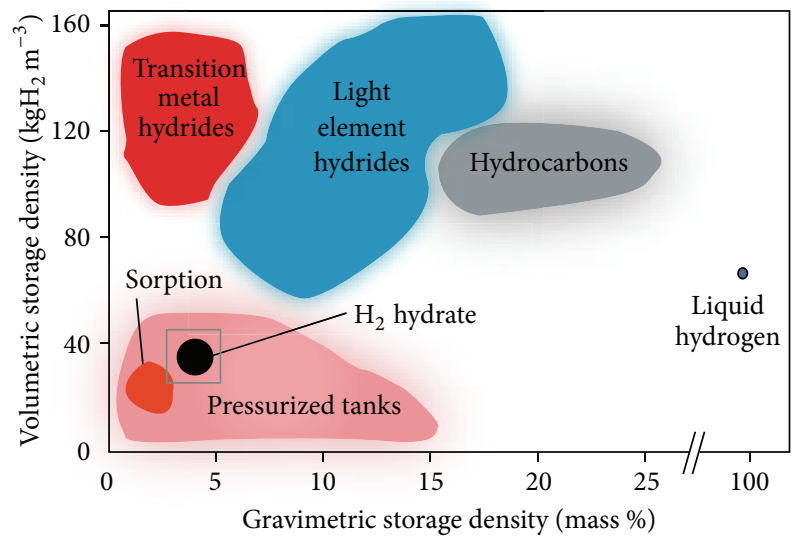

FIGURE 16: The comparison of gravimetric and volumetric storage capacities of clathrate hydrates and other fuels [143].

types of polyhedra, dodecahedra and hexadecahedra, which are, respectively, termed as S (small) and L (large). In general, clathrates are stable only under extremely high pressure conditions, typically of the order of 120 bars. The hydrogen storage properties of clathrate hydrate have gained attention recently, when Lee et al. found that it is possible to stabilize clathrate hydrate at lower pressures by cooccluding large organic molecules, such as tetrahydrofuran (THF) in these caged materials [21]. Complete occupation of all large and small cages of the structure II clathrate hydrate corresponds to $5 \mathrm{wt} \%$ of gravimetric storage capacity (Figure 16) [143].

It can be seen from Figure 16 that the storage capacities of clathrate hydrates presently do not satisfy the 2010 R\&D targets of FreedomCAR. However, if suitable pressure conditions are obtained to stabilize the hydrogen inside the cages, they can offer intermediate solution for the hydrogen storage problem. One of biggest merits of clathrates is that all chemicals required for their formation are inexpensive and easily available. 


\section{Conclusion}

In this review we have presented an overview of the implementation of the hydrogen fuel based energy economy. In the first part we exclusively dealt with the trends of current fossilfuel based energy economy. It was clear that the transition from the present energy economy to a sustainable and cleaner energy such as hydrogen energy is motivated by both economical and environmental factors. Amongst various forms of alternate energies, hydrogen occupies a distinct status, owing to its universal abundance and the highest specific energy. However, the energy density of hydrogen at ambient pressure and temperature conditions is nearly three times lower than that of the conventional fuels. Therefore, to use hydrogen as a fuel, especially in the mobile context, it is vital to improve this storage attribute by several manifolds.

In the second part of the review, we presented the novel solid state hydrogen storage techniques employing carbon nanotubes, metal-doped carbon nanotubes, intermetallic hydrides, metal-organic frameworks, metal-doped metalorganic frameworks, and clathrates. Carbon nanotubes and metal-organic frameworks, in particular the ones doped with transition metal particles, are considered to offer far-reaching solution as a hydrogen storage medium for transportation applications. Other materials discussed in the review are mostly in their preliminary phase and much intensive works are required, for their applications in the mobile hydrogen storage sector.

\section{Conflict of Interests}

The authors declare that there is no conflict of interests regarding the publication of this paper.

\section{References}

[1] J. Yang, A. Sudik, C. Wolverton, and J. S. Donald, "High capacity hydrogen storage materials: attributes for automotive applications and techniques for materials discovery," Chemical Society Reviews, vol. 39, no. 2, pp. 656-675, 2010.

[2] T. Nakata, "Energy-economic models and the environment," Progress in Energy and Combustion Science, vol. 30, no. 4, pp. 417-475, 2004.

[3] U. Jørgensen, "Energy sector in transition-technologies and regulatory policies in flux," Technological Forecasting and Social Change, vol. 72, no. 6, pp. 719-731, 2005.

[4] E. Martinot, "Renewable energy investment by the World Bank," Energy Policy, vol. 29, no. 9, pp. 689-699, 2001.

[5] A. Masini and E. Menichetti, "Investment decisions in the renewable energy sector: an analysis of non-financial drivers," Technological Forecasting \& Social Change, vol. 80, no. 3, pp. 510-524, 2013.

[6] G. D. Berry, A. D. Pasternak, G. D. Rambach, J. R. Smith, and R. N. Schock, "Hydrogen as a future transportation fuel," Energy, vol. 21, no. 4, pp. 289-303, 1996.

[7] B. Johnston, M. C. Mayo, and A. Khare, "Hydrogen: the energy source for the 21 st century," Technovation, vol. 25 , no. 6, pp. 569$585,2005$.

[8] P. Tseng, J. Lee, and P. Friley, "A hydrogen economy: opportunities and challenges," Energy, vol. 30, no. 14, pp. 2703-2720, 2005.
[9] A. Midilli, M. Ay, I. Dincer, and M. A. Rosen, "On hydrogen and hydrogen energy strategies I : current status and needs," Renewable and Sustainable Energy Reviews, vol. 9, no. 3, pp. 255271, 2005.

[10] M. Momirlan and T. N. Veziroglu, "Current status of hydrogen energy," Renewable and Sustainable Energy Reviews, vol. 6, no. 1-2, pp. 141-179, 2002.

[11] L. Zhou, "Progress and problems in hydrogen storage methods," Renewable and Sustainable Energy Reviews, vol. 9, no. 4, pp. 395408, 2005.

[12] P. Chen and M. Zhu, "Recent progress in hydrogen storage," Materials Today, vol. 11, no. 12, pp. 36-43, 2008.

[13] G. Principi, F. Agresti, A. Maddalena, and S. Lo Russo, "The problem of solid state hydrogen storage," Energy, vol. 34, no. 12, pp. 2087-2091, 2009.

[14] W. J. Piel, “Transportation fuels of the future?", Fuel Processing Technology, vol. 71, no. 1-3, pp. 167-179, 2001.

[15] A. E. Farrell, D. W. Keith, and J. Corbett, "A strategy for introducing hydrogen into transportation," Energy Policy, vol. 31, no. 13, pp. 1357-1367, 2003.

[16] A. Züttel, "Materials for hydrogen storage," Materials Today, vol. 6, no. 9, pp. 24-33, 2003.

[17] N. L. Rosi, J. Eckert, M. Eddaoudi et al., "Hydrogen storage in microporous metal-organic frameworks," Science, vol. 300, no. 5622, pp. 1127-1129, 2003.

[18] E. Klontzas, E. Tylianakis, and G. E. Froudakis, "Hydrogen storage in 3D covalent organic frameworks. A multiscale theoretical investigation," Journal of Physical Chemistry C, vol. 112, no. 24, pp. 9095-9098, 2008.

[19] R. Zacharia, S.-U. Rather, S. W. Hwang, and K. S. Nahm, "Spillover of physisorbed hydrogen from sputter-deposited arrays of platinum nanoparticles to multi-walled carbon nanotubes," Chemical Physics Letters, vol. 434, no. 4-6, pp. 286-291, 2007.

[20] J. Weitkamp, M. Fritz, and S. Ernst, "Zeolites as media for hydrogen storage," International Journal of Hydrogen Energy, vol. 20, no. 12, pp. 967-970, 1995.

[21] H. Lee, J.-W. Lee, D. Y. Kim et al., “Tuning clathrate hydrates for hydrogen storage," Nature, vol. 434, no. 7034, pp. 743-746, 2005.

[22] H. Reardon, J. M. Hanlon, R. W. Hughes, A. Godula-Jopek, T. K. Mandal, and D. H. Gregory, "Emerging concepts in solid-state hydrogen storage: the role of nanomaterials design," Energy \& Environmental Science, vol. 5, no. 3, pp. 5951-5979, 2012.

[23] S. H. Sang, H. Furukawa, O. M. Yaghi, and W. A. Goddard III, "Covalent organic frameworks as exceptional hydrogen storage materials," Journal of the American Chemical Society, vol. 130, no. 35, pp. 11580-11581, 2008.

[24] bp, "Putting energy in the spotlight-BP statistical review of World Energy," 2005, http://www.nioclibrary.ir/free-e-resources/BP\%20Statistical\%20Review\%20of\%20World\%20Energy/ statistical_review_of_world_energy_full_report_2005.pdf.

[25] P. Moriarty and D. Honnery, "Hydrogen's role in an uncertain energy future," International Journal of Hydrogen Energy, vol. 34, no. 1, pp. 31-39, 2009.

[26] K. Mazloomi and C. Gomes, "Hydrogen as an energy carrier: prospects and challenges," Renewable and Sustainable Energy Reviews, vol. 16, no. 5, pp. 3024-3033, 2012.

[27] Annual energy outlook 2015, US Energy Information Administration, 2015, http://www.eia.gov/forecasts/aeo/.

[28] K. Mukhopadhyay and O. Forssell, "An empirical investigation of air pollution from fossil fuel combustion and its impact 
on health in India during 1973-1974 to 1996-1997,' Ecological Economics, vol. 55, no. 2, pp. 235-250, 2005.

[29] D. Mage, G. Ozolins, P. Peterson et al., "Urban air pollution in megacities of the world," Atmospheric Environment, vol. 30, no. 5, pp. 681-686, 1996.

[30] J. Alcamo and E. Kreileman, "Emission scenarios and global climate protection," Global Environmental Change, vol. 6, no. 4, pp. 305-334, 1996.

[31] D. G. Kessel, "Global warming_facts, assessment, countermeasures," Journal of Petroleum Science and Engineering, vol. 26, no. 1-4, pp. 157-168, 2000.

[32] O. Kaarstad, "Fossil fuels and responses to global warming," Energy Conversion and Management, vol. 36, no. 6-9, pp. 869872, 1995.

[33] A. D. Sagar, "Automobiles and global warming: alternative fuels and other options for carbon dioxide emissions reduction," Environmental Impact Assessment Review, vol. 15, no. 3, pp. 241274, 1995.

[34] W. R. Moomaw, "Industrial emissions of greenhouse gases," Energy Policy, vol. 24, no. 10-11, pp. 951-968, 1996.

[35] National Energy Policy, Report of the National Energy Policy Development Group, Department of Energy, 2001, https://www .whitehouse.gov/energy.

[36] Hydrogen posture plan, An Integrated Integrated Research, Development and Demonstration Plan, United States Department of Energy, 2006, http://www.hydrogen.energy.gov.

[37] N. Matsuo, "Key elements related to the emissions trading for the Kyoto protocol," Energy Policy, vol. 26, no. 3, pp. 263-273, 1998.

[38] J. Leggett, "A guide to the Kyoto protocol: a treaty with potentially vital strategic implications for the renewables industry," Renewable and Sustainable Energy Reviews, vol. 2, no. 4, pp. 345-351, 1998.

[39] Y. Hu and C. R. Monroy, "Chinese energy and climate policies after Durban: save the Kyoto Protocol," Renewable and Sustainable Energy Reviews, vol. 16, no. 5, pp. 3243-3250, 2012.

[40] K. Vatopoulos, D. Andrews, J. Carlsson, I. Papaioannou, and G. Zubi, Study on the State of Play of Energy Efficiency of Heat and Electricity Production Technologies, European Commission, 2012.

[41] M. Specht, F. Staiss, A. Bandi, and T. Weimer, "Comparison of the renewable transportation fuels, liquid hydrogen and methanol, with gasoline-energetic and economic aspects," International Journal of Hydrogen Energy, vol. 23, no. 5, pp. 387396, 1998.

[42] J. M. Ogden, M. M. Steinbugler, and T. G. Kreutz, "A comparison of hydrogen, methanol and gasoline as fuels for fuel cell vehicles: implications for vehicle design and infrastructure development," Journal of Power Sources, vol. 79, no. 2, pp. 143$168,1999$.

[43] R. L. David, CRC Handbook of Chemistry and Physics, CRC Press, Boca Raton, Fla, USA, 73rd edition, 1992.

[44] L. M. Das, "On-board hydrogen storage systems for automotive application," International Journal of Hydrogen Energy, vol. 21, no. 9, pp. 789-800, 1996.

[45] D. J. Durbin and C. Malardier-Jugroot, "Review of hydrogen storage techniques for on board vehicle applications," International Journal of Hydrogen Energy, vol. 38, no. 34, pp. 1459514617, 2013.

[46] Comparative Properties of Hydrogen and Other Fuels, US Department of Energy, 2015, http://hydrogen.pnl.gov/hydrogendata/comparative-properties-hydrogen-and-other-fuels.
[47] G. A. Karim, "Hydrogen as a spark ignition engine fuel," International Journal of Hydrogen Energy, vol. 28, no. 5, pp. 569577, 2003.

[48] K.-A. Adamson, "Hydrogen from renewable resources-the hundred year commitment," Energy Policy, vol. 32, no. 10, pp. 12311242, 2004.

[49] A. Steinfeld, "Solar thermochemical production of hydrogen-a review," Solar Energy, vol. 78, no. 5, pp. 603-615, 2005.

[50] M. Momirlan and T. Veziroğlu, "Recent directions of world hydrogen production," Renewable \& sustainable energy reviews, vol. 3, no. 2, pp. 219-231, 1999.

[51] A. A. van Benthem, G. J. Kramer, and R. Ramer, "An options approach to investment in a hydrogen infrastructure," Energy Policy, vol. 34, no. 17, pp. 2949-2963, 2006.

[52] J. Tomei, "Planning for a transition to a hydrogen economy: a review of roadmaps," UKSHEC Working Paper 2, 2009.

[53] B. D. Solomon and A. Banerjee, "A global survey of hydrogen energy research, development and policy," Energy Policy, vol. 34, no. 7, pp. 781-792, 2006.

[54] C.-J. Winter, "Hydrogen energy-abundant, efficient, clean: a debate over the energy-system-of-change," International Journal of Hydrogen Energy, vol. 34, no. 14, pp. S1-S2, 2009.

[55] S. O. Akansu, Z. Dulger, N. Kahraman, and T. N. Veziroǧlu, "Internal combustion engines fueled by natural gas-hydrogen mixtures," International Journal of Hydrogen Energy, vol. 29, no. 14, pp. 1527-1539, 2004.

[56] J. W. Heffel, " $\mathrm{NO}_{\mathrm{x}}$ emission and performance data for a hydrogen fueled internal combustion engine at $1500 \mathrm{rpm}$ using exhaust gas recirculation," International Journal of Hydrogen Energy, vol. 28, no. 8, pp. 901-908, 2003.

[57] United States Department of Energy, National Hydrogen Energy Roadmap, 2002, http://www.hydrogen.energy.gov/pdfs/national_ h2_roadmap.pdf.

[58] A. J. Appleby, "Issues in fuel cell commercialization," Journal of Power Sources, vol. 58, no. 2, pp. 153-176, 1996.

[59] C.-J. Winter, "Into the hydrogen energy economy-milestones," International Journal of Hydrogen Energy, vol. 30, no. 7, pp. 681685, 2005.

[60] G. Marbán and T. Valdés-Solís, "Towards the hydrogen economy?” International Journal of Hydrogen Energy, vol. 32, no. 12, pp. 1625-1637, 2007.

[61] D. Day, R. J. Evans, J. W. Lee, and D. Reicosky, "Economical CO $\mathrm{SO}_{x}$, and $\mathrm{NO}_{x}$ capture from fossil-fuel utilization with combined renewable hydrogen production and large-scale carbon sequestration," Energy, vol. 30, no. 14, pp. 2558-2579, 2005.

[62] G. Karagiannakis, C. Kokkofitis, S. Zisekas, and M. Stoukides, "Catalytic and electrocatalytic production of $\mathrm{H}_{2}$ from propane decomposition over $\mathrm{Pt}$ and $\mathrm{Pd}$ in a proton-conducting membrane-reactor," Catalysis Today, vol. 104, no. 2-4, pp. 219224, 2005.

[63] A. I. Miller and R. B. Duffey, "Sustainable and economic hydrogen cogeneration from nuclear energy in competitive power markets," Energy, vol. 30, no. 14, pp. 2690-2702, 2005.

[64] A. Domashenko, A. Golovchenko, Y. Gorbatsky, V. Nelidov, and B. Skorodumov, "Production, storage and transportation of liquid hydrogen. Experience of infrastructure development and operation," International Journal of Hydrogen Energy, vol. 27, no. 7-8, pp. 753-755, 2002.

[65] Air Products and Chemicals Inc, "Hydrogen distribution options," http://www.airproducts.com/products/Gases/Hydrogen .aspx. 
[66] United States Department of Energy, Targets for On-Board Hydrogen Storage Systems for Light Duty Vehicles, United States Department of Energy, 2009, http://www.eere.energy.gov/ hydrogenandfuelcells/pdfs/.

[67] K. Pehr, P. Sauermann, O. Traeger, and M. Bracha, "Liquid hydrogen for motor vehicles-the world's first public LH2 filling station," International Journal of Hydrogen Energy, vol. 26, no. 7, pp. 777-782, 2001.

[68] S. A. Sherif, N. Zeytinoglu, and T. N. Veziroğlu, "Liquid hydrogen: potential, problems, and a proposed research program," International Journal of Hydrogen Energy, vol. 22, no. 7, pp. 683$688,1997$.

[69] M. R. Swain, P. Filoso, E. S. Grilliot, and M. N. Swain, "Hydrogen leakage into simple geometric enclosures," International Journal of Hydrogen Energy, vol. 28, no. 2, pp. 229-248, 2003.

[70] K. Verfondern and B. Dienhart, "Experimental and theoretical investigation of liquid hydrogen pool spreading and vaporization," International Journal of Hydrogen Energy, vol. 22, no. 7, pp. 649-660, 1997.

[71] F. Rigas and S. Sklavounos, "Evaluation of hazards associated with hydrogen storage facilities," International Journal of Hydrogen Energy, vol. 30, no. 13-14, pp. 1501-1510, 2005.

[72] H. W. Pohl and V. V. Malychev, "Hydrogen in future civil aviation," International Journal of Hydrogen Energy, vol. 22, no. 10-11, pp. 1061-1069, 1997.

[73] A. Contreras, S. Yiğit, K. Özay, and T. N. Veziroğlu, "Hydrogen as aviation fuel: a comparison with hydrocarbon fuels," International Journal of Hydrogen Energy, vol. 22, no. 10-11, pp. 10531060, 1997.

[74] C. E. Borroni-Bird, "Fuel cell commercialization issues for lightduty vehicle applications," Journal of Power Sources, vol. 61, no. 1-2, pp. 33-48, 1996.

[75] T. E. Lipman, J. L. Edwards, and D. M. Kammen, "Fuel cell system economics: comparing the costs of generating power with stationary and motor vehicle PEM fuel cell systems," Energy Policy, vol. 32, no. 1, pp. 101-125, 2004.

[76] California Hydrogen Highway Network Initiative, http://www .hydrogenhighway.ca.gov/.

[77] Department of Energy, Target Explanation Document: Onboard Hydrogen Storage for Light-Duty Fuel Cell Vehicles, Department of Energy, 2015, http://energy.gov/sites/prod/files/ 2015/05/f22/fcto_targets_onboard_hydro_storage_explanation .pdf.

[78] Multi-Year Research, Development and Demonstration Plan, 2012, http://energy.gov/sites/prod/files/2014/03/f12/introduction.pdf.

[79] S. Satyapal, J. Petrovic, C. Read, G. Thomas, and G. Ordaz, "The U.S. Department of Energy's National Hydrogen Storage Project: progress towards meeting hydrogen-powered vehicle requirements," Catalysis Today, vol. 120, no. 3-4, pp. 246-256, 2007.

[80] J. L. Mendoza-Cortes, W. A. Goddard, H. Furukawa, and O. M. Yaghi, "A covalent organic framework that exceeds the DOE 2015 volumetric target for $\mathrm{H}_{2}$ uptake at $298 \mathrm{~K}$," The Journal of Physical Chemistry Letters, vol. 3, no. 18, pp. 2671-2675, 2012.

[81] T. N. Veziroglu, S. Y. Zaginaichenko, D. V. Schur et al., Hydrogen Materials Science and Chemistry of Carbon Nanomaterials, Springer, Dordrecht, The Netherlands, 2005.

[82] D. Stolten, "Hydrogen and fuel cells: fundamentals, technologies and applications," Angewandte Chemie, vol. 50, no. 42, p. 9787, 2011.
[83] R. Ewald, "Requirements for advanced mobile storage systems," International Journal of Hydrogen Energy, vol. 23, no. 9, pp. 803814, 1998.

[84] M. T. Syed, S. A. Sherif, T. N. Veziroglu, and J. W. Sheffield, "An economic analysis of three hydrogen liquefaction systems," International Journal of Hydrogen Energy, vol. 23, no. 7, pp. 565576, 1998.

[85] M. B. Ley, L. H. Jepsen, Y.-S. Lee et al., "Complex hydrides for hydrogen storage-new perspectives," Materials Today, vol. 17, no. 3, pp. 122-128, 2014.

[86] B. Sakintuna, F. Lamari-Darkrim, and M. Hirscher, "Metal hydride materials for solid hydrogen storage: a review," International Journal of Hydrogen Energy, vol. 32, no. 9, pp. 1121-1140, 2007.

[87] S.-U. Rather, R. Zacharia, S. W. Hwang, M.-U. Naik, and K. S. Nahm, "Hyperstoichiometric hydrogen storage in monodispersed palladium nanoparticles," Chemical Physics Letters, vol. 438, no. 1-3, pp. 78-84, 2007.

[88] A. Züttel, A. Borgschulte, and L. Schlapbach, Hydrogen as a Future Energy Carrier, Wiley, Chichester, UK, 2008.

[89] M. Morinaga, H. Yukawa, K. Nakatsuka, and M. Takagi, "Roles of constituent elements and design of hydrogen storage alloys," Journal of Alloys and Compounds, vol. 330-332, pp. 20-24, 2002.

[90] M. E. Arroyo y de Dompablo and G. Ceder, "First principles investigations of complex hydrides $\mathrm{AMH}_{4}$ and $\mathrm{A}_{3} \mathrm{MH}_{6}(\mathrm{~A}=\mathrm{Li}$, $\mathrm{Na}, \mathrm{K}, \mathrm{M}=\mathrm{B}, \mathrm{Al}, \mathrm{Ga}$ ) as hydrogen storage systems," Journal of Alloys and Compounds, vol. 364, no. 1-2, pp. 6-12, 2004.

[91] A. Züttel, S. Rentsch, P. Fischer et al., "Hydrogen storage properties of LiBH4," Journal of Alloys and Compounds, vol. 356-357, pp. 515-520, 2003.

[92] S.-I. Orimo, Y. Nakamori, J. R. Eliseo, A. Züttel, and C. M. Jensen, "Complex hydrides for hydrogen storage," Chemical Reviews, vol. 107, no. 10, pp. 4111-4132, 2007.

[93] IPHE International Hydrogen Storage Technology Conference, Lucca, Italy, June 2005.

[94] Technical System Targets: Onboard Hydrogen Storage for Light-Duty Fuel Cell Vehicles, 2012, http://www.energy.gov.

[95] R. G. Ding, J. J. Finnerty, Z. H. Zhu, Z. F. Yan, and G. Q. Lu, Encyclopedia of Nanoscience and Nanotechnology, American Scientific Publishers, 2004.

[96] R. Ghosh, T. Maruyama, H. Kondo, K. Kimoto, T. Nagai, and S. Iijima, "Synthesis of single-walled carbon nanotubes on graphene layers," Chemical Communications, vol. 51, no. 43, pp. 8974-8977, 2015.

[97] K. A. Williams and P. C. Eklund, "Monte Carlo simulations of $\mathrm{H}_{2}$ physisorption in finite-diameter carbon nanotube ropes," Chemical Physics Letters, vol. 320, no. 3-4, pp. 352-358, 2000.

[98] A. C. Dillon, K. M. Jones, T. A. Bekkedahl, C. H. Kiang, D. S. Bethune, and M. J. Heben, "Storage of hydrogen in single-walled carbon nanotubes," Nature, vol. 386, no. 6623, pp. 377-379, 1997.

[99] K. Shindo, T. Kondo, and Y. Sakurai, "Hydrogen physisorption capacities of mechanically milled activated carbon powders in a $\mathrm{H} 2$ atmosphere using a gravimetric method," Journal of Alloys and Compounds, vol. 379, no. 1-2, pp. 252-255, 2004.

[100] Y. Ye, C. C. Ahn, C. Witham et al., "Hydrogen adsorption and cohesive energy of single-walled carbon nanotubes," Applied Physics Letters, vol. 74, no. 16, pp. 2307-2309, 1999.

[101] A. Badzian, T. Badzian, E. Breval, and A. Piotrowski, "Nanostructured, nitrogen-doped carbon materials for hydrogen storage," Thin Solid Films, vol. 398-399, pp. 170-174, 2001. 
[102] N. Rajalakshmi, K. S. Dhathathreyan, A. Govindaraj, and B. C. Satishkumar, "Electrochemical investigation of single-walled carbon nanotubes for hydrogen storage," Electrochimica Acta, vol. 45, no. 27, pp. 4511-4515, 2000.

[103] C. Nützenadel, A. Züttel, D. Chartouni, and L. Schlapbach, "Electrochemical storage of hydrogen in nanotube materials," Electrochemical and Solid-State Letters, vol. 2, no. 1, pp. 30-32, 1999.

[104] P. F. Weck, E. Kim, N. Balakrishnan, H. Cheng, and B. I. Yakobson, "Designing carbon nanoframeworks tailored for hydrogen storage," Chemical Physics Letters, vol. 439, no. 4-6, pp. 354-359, 2007.

[105] B. Adeniran and R. Mokaya, "Low temperature synthesized carbon nanotube superstructures with superior $\mathrm{CO}_{2}$ and hydrogen storage capacity," Journal of Materials Chemistry A, vol. 3, no. 9, pp. 5148-5161, 2015.

[106] W. Z. Huang, X. B. Zhang, J. P. Tu et al., "The effect of pretreatments on hydrogen adsorption of multi-walled carbon nanotubes," Materials Chemistry and Physics, vol. 78, no. 1, pp. 144-148, 2003.

[107] F. Liu, X. Zhang, J. Cheng et al., "Preparation of short carbon nanotubes by mechanical ball milling and their hydrogen adsorption behavior," Carbon, vol. 41, no. 13, pp. 2527-2532, 2003.

[108] Y. Xia, J. Z. Zhu, M. Zhao et al., "Enhancement of hydrogen physisorption on single-walled carbon nanotubes resulting from defects created by carbon bombardment," Physical Review B-Condensed Matter and Materials Physics, vol. 71, no. 7-15, Article ID 075412, 2005.

[109] S. Orimo, T. Matsushima, H. Fujii, T. Fukunaga, and G. Majer, "Hydrogen desorption property of mechanically prepared nanostructured graphite," Journal of Applied Physics, vol. 90, no. 3, pp. 1545-1549, 2001.

[110] R. Zacharia, K. Y. Kim, A. K. M. Fazle Kibria, and K. S. Nahm, "Enhancement of hydrogen storage capacity of carbon nanotubes via spill-over from vanadium and palladium nanoparticles," Chemical Physics Letters, vol. 412, no. 4-6, pp. 369-375, 2005.

[111] A. Lueking and R. T. Yang, "Hydrogen storage in carbon nanotubes: residual metal content and pretreatment temperature," AIChE Journal, vol. 49, no. 6, pp. 1556-1568, 2003.

[112] A. Lueking and R. T. Yang, "Evidence of hydrogen spillover onto carbon nanotubes in the presence of nickel," Journal of Catalysis, vol. 165, p. 206, 2002.

[113] R. Bhowmick, S. Rajasekaran, D. Friebel et al., "Hydrogen spillover in Pt-single-walled carbon nanotube composites: formation of stable C-H bonds," Journal of the American Chemical Society, vol. 133, no. 14, pp. 5580-5586, 2011.

[114] J. A. Schwarz, C. I. Contescu, and K. Putyera, Dekker Encyclopedia of Nanoscience and Nanotechnology, vol. 1, CRC Press, New York, NY, USA, 2004.

[115] Y. Zhang, N. W. Franklin, R. J. Chen, and H. Dai, "Metal coating on suspended carbon nanotubes and its implication to metaltube interaction," Chemical Physics Letters, vol. 331, no. 1, pp. 3541, 2000.

[116] V. B. Parambhath, R. Nagar, K. Sethupathi, and S. Ramaprabhu, "Investigation of spillover mechanism in palladium decorated hydrogen exfoliated functionalized graphene," Journal of Physical Chemistry C, vol. 115, no. 31, pp. 15679-15685, 2011.

[117] T. Yildirim and S. Ciraci, "Titanium-decorated carbon nanotubes as a potential high-capacity hydrogen storage medium," Physical Review Letters, vol. 94, no. 17, Article ID 175501, 2005.
[118] C. Liu, Y. Chen, C.-Z. Wu, S.-T. Xu, and H.-M. Cheng, "Hydrogen storage in carbon nanotubes revisited," Carbon, vol. 48, no. 2, pp. 452-455, 2010.

[119] A. C. Dillon, K. E. H. Gilbert, J. L. Alleman et al., "Carbon nanotube materials for hydrogen storage," in Proceedings of the Hydrogen Program Review, National Renewable Energy Laboratory, San Ramon, Calif, USA, May 2000.

[120] C. Zhang, X. Lu, and A. Gu, "How to accurately determine the uptake of hydrogen in carbonaceous materials," International Journal of Hydrogen Energy, vol. 29, no. 12, pp. 1271-1276, 2004.

[121] M. Eddaoudi, J. Kim, N. Rosi et al., "Systematic design of pore size and functionality in isoreticular MOFs and their application in methane storage," Science, vol. 295, no. 5554, pp. 469-472, 2002.

[122] M. Kurmoo, "Magnetic metal-organic frameworks," Chemical Society Reviews, vol. 38, no. 5, pp. 1353-1379, 2009.

[123] J. L. C. Rowsell and O. M. Yaghi, "Metal—organic frameworks: a new class of porous materials," Microporous and Mesoporous Materials, vol. 73, no. 1-2, pp. 3-14, 2004.

[124] W. Lu, Z. Wei, Z.-Y. Gu et al., "Tuning the structure and function of metal-organic frameworks via linker design," Chemical Society Reviews, vol. 43, no. 16, pp. 5561-5593, 2014.

[125] B. Panella and M. Hirscher, "Hydrogen physisorption in metalorganic porous crystals," Advanced Materials, vol. 17, no. 5, pp. 538-541, 2005.

[126] N. Stock and S. Biswas, "Synthesis of metal-organic frameworks (MOFs): routes to various MOF topologies, morphologies, and composites," Chemical Reviews, vol. 112, no. 2, pp. 933-969, 2012.

[127] H. W. Langmi, J. Ren, B. North, M. Mathe, and D. Bessarabov, "Hydrogen storage in metal-organic frameworks: a review," Electrochimica Acta, vol. 128, pp. 368-392, 2014.

[128] L. J. Murray, M. Dinc, and J. R. Long, "Hydrogen storage in metal-organic frameworks," Chemical Society Reviews, vol. 38, no. 5, pp. 1294-1314, 2009.

[129] L. Pan, M. B. Sander, X. Huang et al., "Microporous metal organic materials: promising candidates as sorbents for hydrogen storage," Journal of the American Chemical Society, vol. 126, no. 5, pp. 1308-1309, 2004.

[130] T. Yildirim and M. R. Hartman, "Direct observation of hydrogen adsorption sites and nanocage formation in metal-organic frameworks," Physical Review Letters, vol. 95, no. 21, Article ID 215504, 2005.

[131] S. B. Kalidindi and R. A. Fischer, "Covalent organic frameworks and their metal nanoparticle composites: prospects for hydrogen storage," Physica Status Solidi B, vol. 250, no. 6, pp. 1119-1127, 2013.

[132] S. S. Han, H. Furukawa, O. M. Yaghi, and W. A. Goddard III, "Covalent organic frameworks as exceptional hydrogen storage materials," Journal of the American Chemical Society, vol. 130, no. 35, pp. 11580-11581, 2008.

[133] S.-Y. Ding and W. Wang, "Covalent organic frameworks (COFs): from design to applications," Chemical Society Reviews, vol. 42, no. 2, pp. 548-568, 2013.

[134] T. Stergiannakos, E. Tylianakis, E. Klontzas, P. N. Trikalitis, and G. E. Froudakis, "Hydrogen storage in novel li-doped corrole metal-organic frameworks," The Journal of Physical Chemistry C, vol. 116, no. 15, pp. 8359-8363, 2012.

[135] X. M. Liu, S.-U. Rather, Q. Li, A. Lueking, Y. Zhao, and J. Li, "Hydrogenation of CuBTC framework with the introduction of a PtC hydrogen spillover catalyst," The Journal of Physical Chemistry C, vol. 116, no. 5, pp. 3477-3485, 2012. 
[136] W. Qin, W. Cao, H. Liu, Z. Li, and Y. Li, "Metal-organic framework MIL-101 doped with palladium for toluene adsorption and hydrogen storage," Royal Society of Chemistry Advances, vol. 4, pp. 2414-2420, 2014.

[137] N. R. Stuckert, L. Wang, and R. T. Yang, "Characteristics of hydrogen storage by spillover on Pt-doped carbon and catalystbridged metal organic framework," Langmuir, vol. 26, no. 14, pp. 11963-11971, 2010.

[138] F. Schröder and R. A. Fischer, "Doping of metal-organic frameworks with functional guest molecules and nanoparticles," in Functional Metal-Organic Frameworks: Gas Storage, Separation and Catalysis, vol. 293 of Topics in Current Chemistry, pp. 77-113, Springer, Berlin, Germany, 2010.

[139] Y. Li and R. T. Yang, "Hydrogen storage in metal-organic and covalent-organic frameworks by spillover," AIChE Journal, vol. 54, no. 1, pp. 269-279, 2008.

[140] Y. Li and R. T. Yang, "Significantly enhanced hydrogen storage in metal-organic frameworks via spillover," Journal of the American Chemical Society, vol. 128, no. 3, pp. 726-727, 2006.

[141] A. J. Lachawiec Jr., G. Qi, and R. T. Yang, "Hydrogen storage in nanostructured carbons by spillover: bridge-building enhancement," Langmuir, vol. 21, no. 24, pp. 11418-11424, 2005.

[142] F. H. Herbstein, Crystalline Molecular Complexes and Compounds: and Principles, vol. 1, 2005.

[143] F. Schüth, “Technology: hydrogen and hydrates," Nature, vol. 434, no. 7034, pp. 712-713, 2005. 

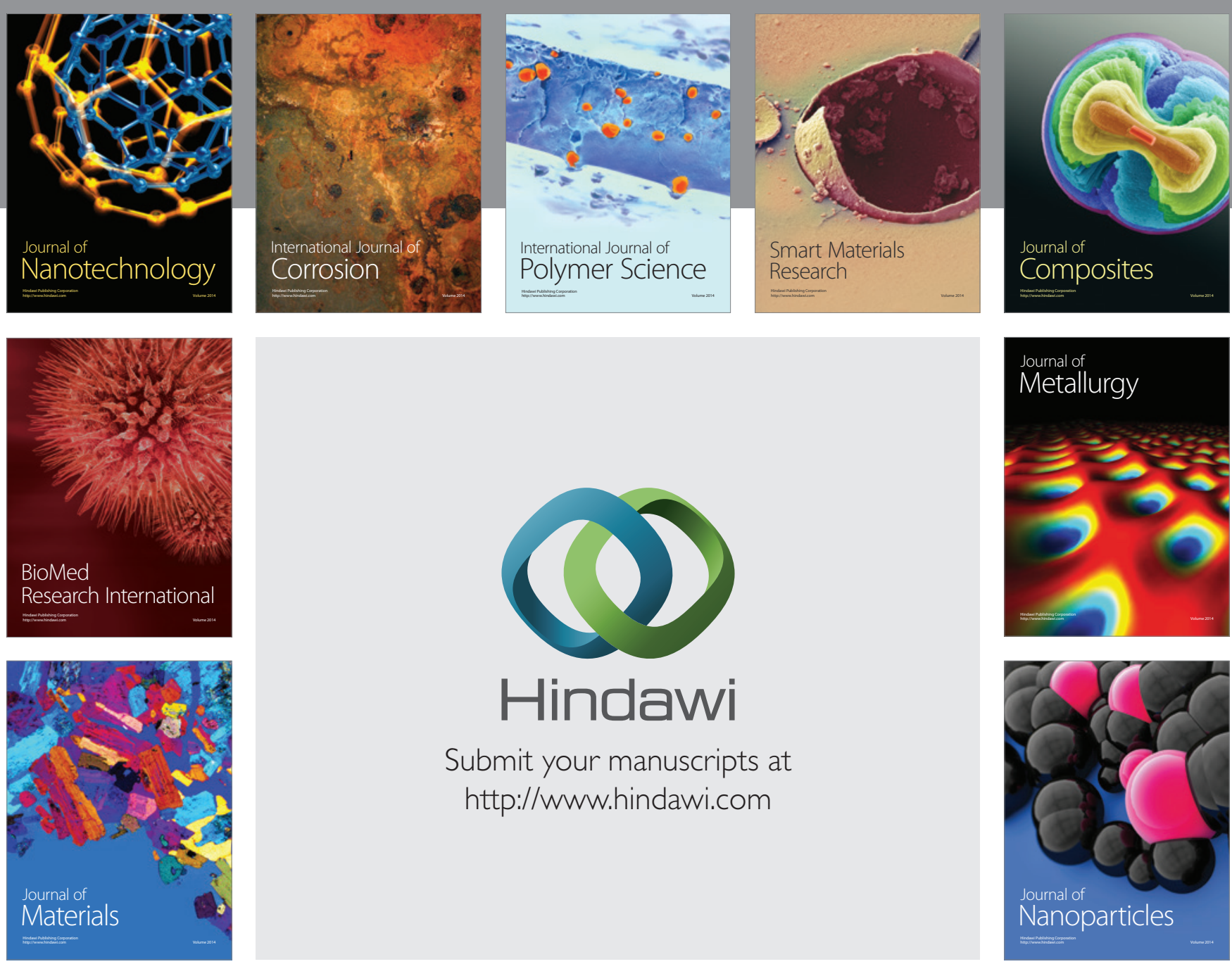

Submit your manuscripts at http://www.hindawi.com
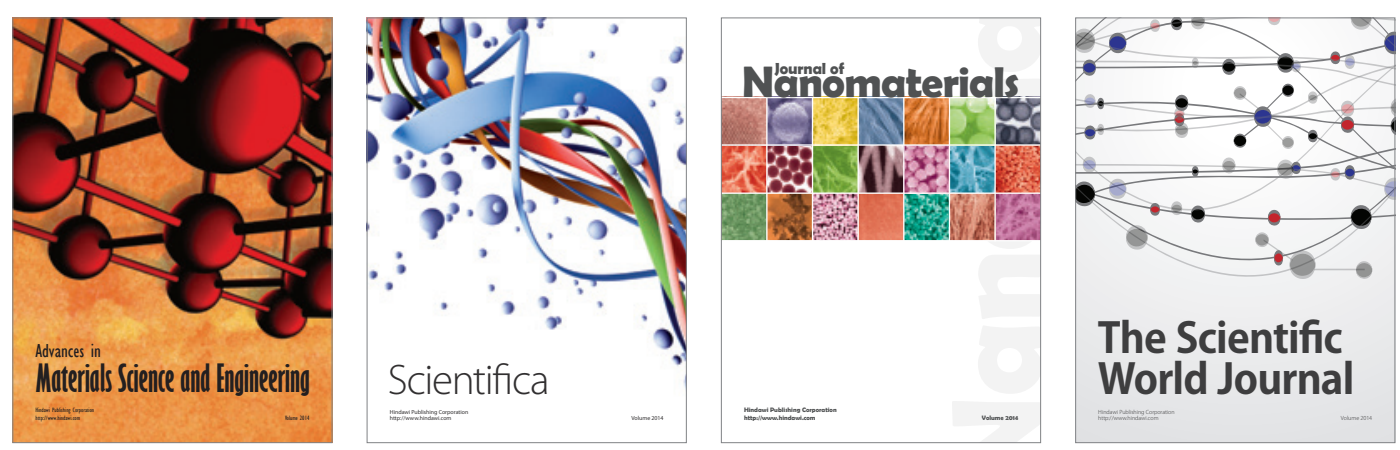

\section{The Scientific World Journal}
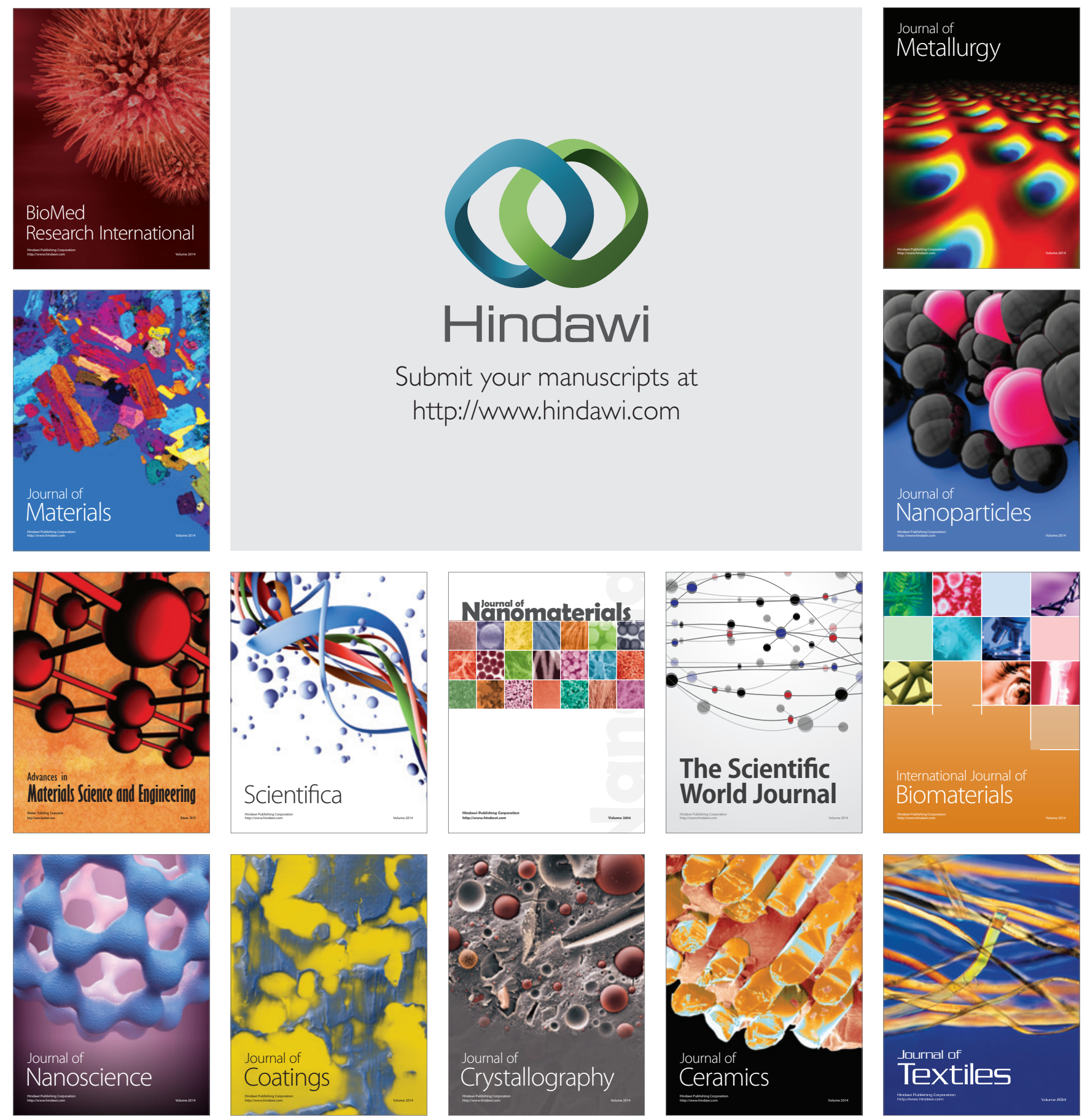